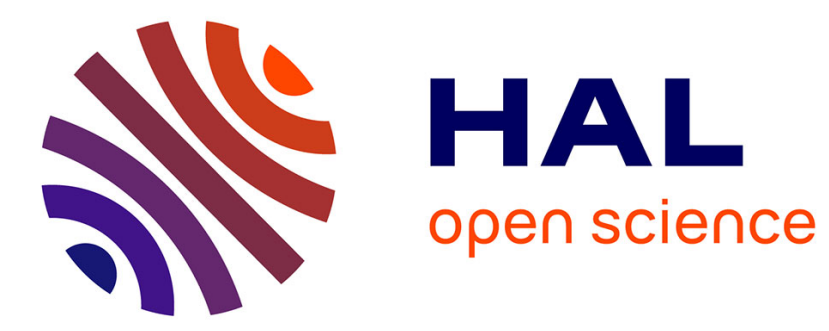

\title{
Microphysical and optical properties of atmospheric ice crystals at South Pole Station.
}

\author{
R.P. Lawson, B.A. Baker, P. Zmarly, D. O'Connor, Q. Mo, Jean-François
}

Gayet, Valery Shcherbakov

\section{- To cite this version:}

R.P. Lawson, B.A. Baker, P. Zmarly, D. O'Connor, Q. Mo, et al.. Microphysical and optical properties of atmospheric ice crystals at South Pole Station.. Journal of Applied Meteorology and Climatology, 2006, 45 (11), pp.1505-1524. 10.1175/JAM2421.1 . insu-00152567

\section{HAL Id: insu-00152567 https://hal-insu.archives-ouvertes.fr/insu-00152567}

Submitted on 10 Mar 2021

HAL is a multi-disciplinary open access archive for the deposit and dissemination of scientific research documents, whether they are published or not. The documents may come from teaching and research institutions in France or abroad, or from public or private research centers.
L'archive ouverte pluridisciplinaire HAL, est destinée au dépôt et à la diffusion de documents scientifiques de niveau recherche, publiés ou non, émanant des établissements d'enseignement et de recherche français ou étrangers, des laboratoires publics ou privés. 


\title{
Microphysical and Optical Properties of Atmospheric Ice Crystals at South Pole Station
}

\author{
R. Paul Lawson, Brad A. Baker, Patrick Zmarzly, Darren O’Connor, and Qixu Mo \\ SPEC, Inc., Boulder, Colorado \\ JEAN-Francois GAYET \\ Laboratoire de Météorologie Physique, UMR 6016, CNRS/Université Blaise Pascal, Clermont-Ferrand, France
}

VALERY SHCHERBAKOV

Institute of Physics, Minsk, Belarus

(Manuscript received 11 March 2005, in final form 22 March 2006)

\begin{abstract}
In early February 2001 (during the austral summer), over 900000 digital images of ice crystals were recorded at the South Pole using two ground-based cloud particle imagers (CPIs). Of these, 721572 crystals $>50 \mu \mathrm{m}$ were classified into crystal habits. When sorted by number, $30 \%$ of the crystals were rosette shaped (mixed-habit rosettes, platelike polycrystals, and rosette shapes with side planes), $45 \%$ were diamond dust (columns, thick plates, and plates), and $25 \%$ were irregular. When sorted by area, rosette shapes comprised $50 \%$, diamond dust $30 \%$ and irregular $20 \%$. By mass, the percentages were $57 \%$ rosette shapes, $23 \%$ diamond dust, and $20 \%$ irregular. Particle size distributions as a function of maximum dimension and equivalent radius are compared with previous studies. Particles are generally found to be slightly larger than previous austral wintertime studies. In 2002, a polar nephelometer (PN) that measures scattering phase function was incorporated with one of the CPIs. Correlated measurements between the two instruments showed that $22^{\circ}$ and $46^{\circ}$ peaks in the phase function were present when diamond dust was recorded by the CPI, but not when rosette shapes were present. Visual observations confirmed the presence of $22^{\circ}$ and $46^{\circ}$ atmospheric halos in some, but not all, of the diamond dust events. No visual halos were observed when rosette shapes were precipitating. Average PN phase functions are presented for diamond dust and rosette shapes. The diamond dust and rosette-shaped ice crystals appear to be very similar in shape to those observed by CPIs in cirrus clouds. Cloud conditions at the South Pole that were associated with various crystal types are discussed, as are some effects of blowing snow.
\end{abstract}

\section{Introduction}

SPEC, Inc., collected unique measurements of the size, shape, and concentration of over 900000 ice crystals at the South Pole Station (SPS) from 1 to 8 February 2001. In 2001, SPEC operated two cloud particle imagers (CPIs) (Lawson et al. 2001), and in February 2002 measurements from a polar nephelometer (PN) (Gayet et al. 1997) that measures scattering phase function were added. The surface temperature during the

Corresponding author address: R. Paul Lawson, SPEC, Inc., 3022 Sterling Circle, Suite 200, Boulder, CO 80301.

E-mail: plawson@specinc.com period of observation reported here, 1-8 February 2001 , ranged from $-30^{\circ}$ to $-39^{\circ} \mathrm{C}$.

The size, shape, concentration, and light-scattering properties (i.e., phase function) of ice crystals have a major impact on the earth's radiation budget. For example, Liou (1986) showed that cirrus particles play an important role in the energy balance of the earth-atmosphere system through their interactions with solar and terrestrial radiation. Stephens et al. (1990) concluded that prediction of cirrus cloud feedback on climate is limited by our lack of understanding of the relationship between the size and shape of ice crystals, and the gross radiative properties of cirrus. Labonnote et al. (2000) determined that accurate measurements of the size and shape of cirrus particles were essential to obtain reli- 
able inversion products from remote observations. Kristjánsson et al. (2000) used climate models to show that the treatment of ice particle size and habit may have a significant impact on climate change. Calculations shown in Mishchenko et al. (1996) suggest that using the wrong scattering phase function in retrieving cloud optical thickness can result in an overestimation or underestimation of optical thickness by more than a factor of 3.

Detailed measurements of the size, shape, and scattering phase function of ice crystals at SPS can be adapted to studies of the optical properties of ice crystals in cirrus and other ice clouds. The elevation of SPS is approximately $2.8 \mathrm{~km}$ from mean sea level (MSL), and the temperature in the first $5 \mathrm{~km} \mathrm{MSL}$ of the atmosphere generally ranges from approximately $-32^{\circ}$ to $-40^{\circ} \mathrm{C}$ in February (Warren 1996). Clouds that form in the lower $3 \mathrm{~km}$ above ground level (AGL) over the SPS in February often have the appearance of supercooled stratus clouds and cirrus. In the cold atmosphere, ice crystals form in these clouds (and occasionally in summertime cloudless air), fall to the surface, and can easily be observed.

The shapes of the ice crystals falling at SPS often appear to be very similar to those observed in cirrus clouds. For example, recent studies using a CPI show that the most common crystal type (weighted by area and mass) in midlatitude cirrus is the rosette shape (Lawson et al. 2006). Adopting the nomenclature of Bailey and Hallett (2004), here we define rosette shapes to include mixed-habit rosettes and platelike polycrystals, which often contain side planes. Pure rosettes, according to Bailey and Hallett (2004), typically grow within the temperature range from $-40^{\circ}$ to $-55^{\circ} \mathrm{C}$, and are an assemblage of columns with bulletlike ends that join at a central point. Our observations support the laboratory findings of Bailey and Hallett (2004); pure bullet rosettes are rarely (but occasionally) observed to grow at temperatures warmer than $-40^{\circ} \mathrm{C}$ (see Baker and Lawson 2006a; Lawson et al. 2006). Rosette-shaped crystals were often observed at SPS in 2001 and 2002, probably nucleated in supercooled water clouds (Mahesh et al. 2001), usually within the temperature range from $-30^{\circ}$ to $-40^{\circ} \mathrm{C}$, and within $1 \mathrm{~km}$ of the surface. Other crystal habits, such as columns and plates, although not observed as frequently in midlatitude cirrus (Lawson et al. 2006), are also observed at SPS, often falling from thin, cold clouds that have the same appearance as cirrus.

Previous studies that focused on analysis of ice crystals at SPS have relied on collecting the crystals on glass slides or Formvar replicas and photographing them under a microscope (e.g., Shimizu 1963; Kikuchi 1970;
Hogan 1975; Kikuchi and Hogan 1979; Ohtake 1978; Ohtake and Yogi 1979; Smiley et al. 1980; Inoue et al. 1984; Tape 1994; Walden et al. 2003, hereinafter W03). Except for the more recent work by W03, all of these studies have sized and classified the crystals manually. W03 collected about 20000 ice crystals at SPS on glass slides during the winter of 1992, when surface temperatures ranged from $-35^{\circ}$ to $-73^{\circ} \mathrm{C}$. They digitized the images with software that sized individual particles using a computer mouse to draw vectors across the image. Bromwich (1988) gives summary information on all of these studies, except for Tape (1994) and W03.

Hogan (1975) classified ice crystals into diamond dust, combinations of bullets, and columns from 27 January through 2 February 1974. His Fig. 4 shows that combinations of bullets were observed most frequently. Hogan notes that the $650-600-\mathrm{hPa}$ layer was supersaturated with respect to ice during the entire observation period. He states that cirrus cloud cover was observed at all times when precipitation was occurring and precipitation ceased with the disappearance of cirrus cloud cover. Kikuchi and Hogan (1979) report results similar to Hogan (1975) based on a 30-day deployment during January-February 1975. However, they make note that on one day, 29 January 1975, diamond dust was observed to precipitate under a cloudless sky. Ohtake (1978) and Ohtake and Yogi (1979) studied ice crystals at SPS during the Antarctic summers from 1974 to 1977. They observed that assemblages of bullets were the most common and also the largest (about $1 \mathrm{~mm}$ or larger) of all of the ice crystals observed in winter and summer. The assemblages of bullets were associated with cirrus and cirrostratus cloud layers at heights of 1-3 km above the surface and 500-hPa temperatures from $-40^{\circ}$ to $-55^{\circ} \mathrm{C}$. They concluded that the assemblages of bullets contributed the large majority of the mass of SPS precipitation. They observed combined ice crystals in the form of side planes, bullets, and columns with moist upper air at about $670 \mathrm{hPa}$ at temperatures from $-35^{\circ}$ to $-45^{\circ} \mathrm{C}$ in cloud layers from $300 \mathrm{~m}$ to $1 \mathrm{~km}$ about the surface. In the summer, they observed hexagonal plates and columns smaller than $200 \mu \mathrm{m}$ (referred to as diamond dust by W03 and in this work). The diamond dust was typically associated with either stratus fractus or clear skies, but they report that low stratus clouds not visible over the horizon may have been associated with the precipitating diamond dust.

W03 divided the crystal types into three main categories-diamond dust, blowing snow, and snow grainsand found that the predominant crystal types are hexagonal columns and plates and rounded particles of blowing snow. Blowing snow dominated the number percentage $(74 \%)$ and contribution to area $(46 \%)$, 

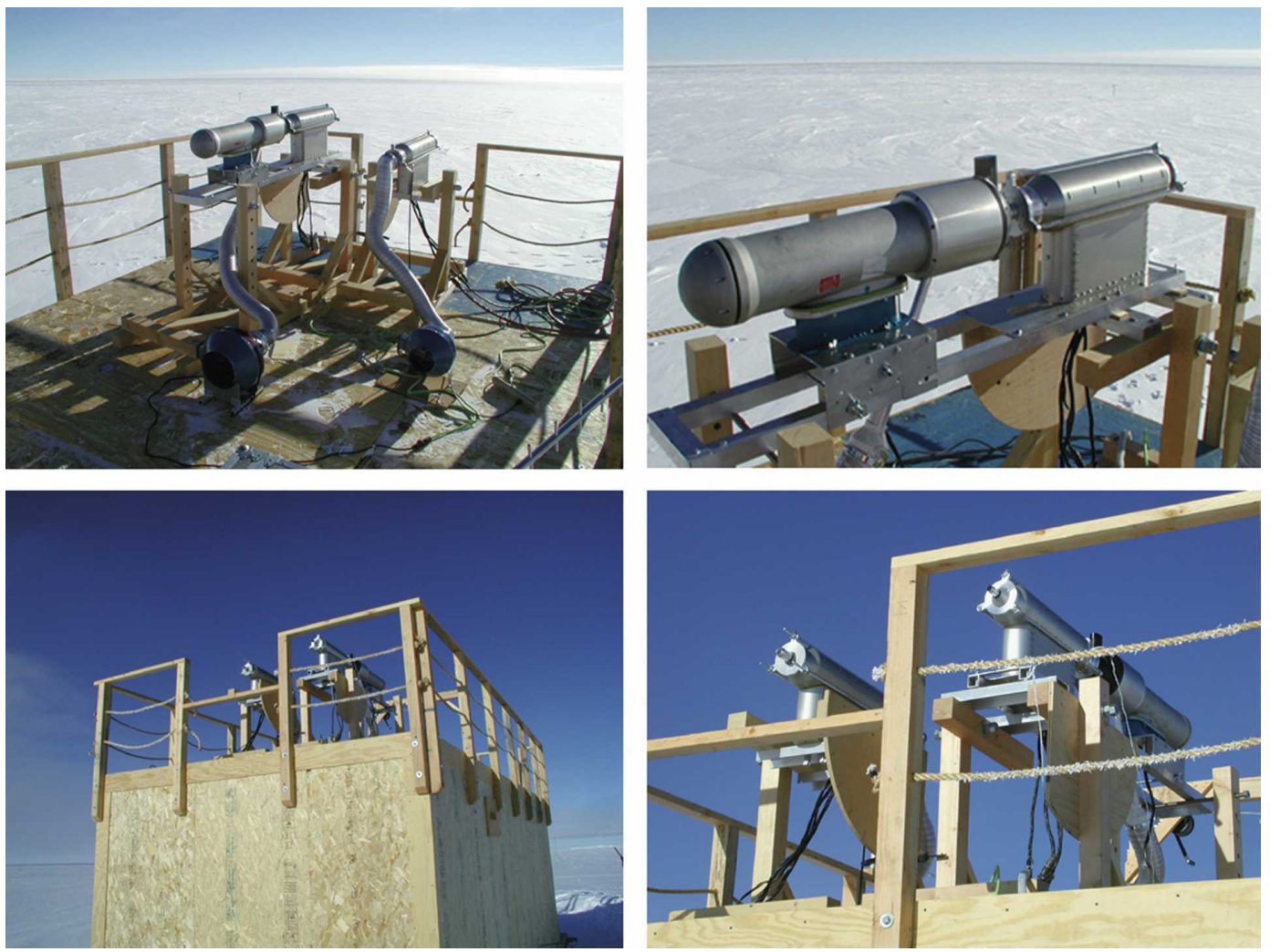

FIG. 1. Photographs of the SPEC CPIs and LaMP PN on top of a small building at the South Pole. The PN is seen connected to the exhaust region of the CPI in the panel at the upper left. Both instruments are aspirated using an exhaust fan. The sampling elevation is approximately $3 \mathrm{~m}$.

which may be expected because winds at SPS are generally higher in the winter than in the summer (Warren 1996). However, even though there were only 67 bullet clusters out of a total of about 20000 crystals, they accounted for the largest individual crystal mass percentage $(39 \%)$. W03 reported that, overall, diamond dust crystals were smaller in winter than summertime at SPS. They also show particle size distributions as a function of equivalent particle radius; their results are discussed and compared with our results in section 3c.

\section{Instrumentation}

Figure 1 shows photographs of the CPIs and polar nephelometer installed on the roof of a small building at the SPS. The PN and the CPI were connected together using a custom-designed plumbing system with inlet funnels to maximize the probability that particles would pass through the sample volumes of both the CPI and PN. Constant-flow exhaust fans were connected to the exit regions of the CPIs. Before the plumbing system was fabricated out of aluminum, the plumbing system and the sample tubes of the CPI and PN were constructed using Plexiglas so that flow within the system could be visualized. A fog generator was used to make a cloud that could be viewed using a laser illumination system. The flow visualization tests showed that the sample air reliably passed through both the CPI and $\mathrm{PN}$ viewing areas. The aluminum plumbing was fabricated and the flow rate through the system was measured using miniature pitot tubes. Figure 2 shows the velocity profiles measured in the sample volumes of the $\mathrm{CPI}$ and PN. The measurements show that the velocity profiles in each instrument are relatively flat and that the measurements were repeatable. It should be noted, however, that these measurements did not account for the effects of ambient wind velocity and direction, which can have a significant effect on particle flow rate.

The CPI casts an image of a particle on a solid-state $1024 \times 1024$ pixel digital charge-coupled device $(\mathrm{CCD})$ camera by freezing the motion of the particle using a 40-ns-pulsed high-power laser diode. As shown in the conceptual drawing in Fig. 3, a particle detection system (PDS) with upstream lasers precisely defines the focal plane (which is canted at a $45^{\circ}$ angle) so that at least one particle in the image is almost always in focus. Each 

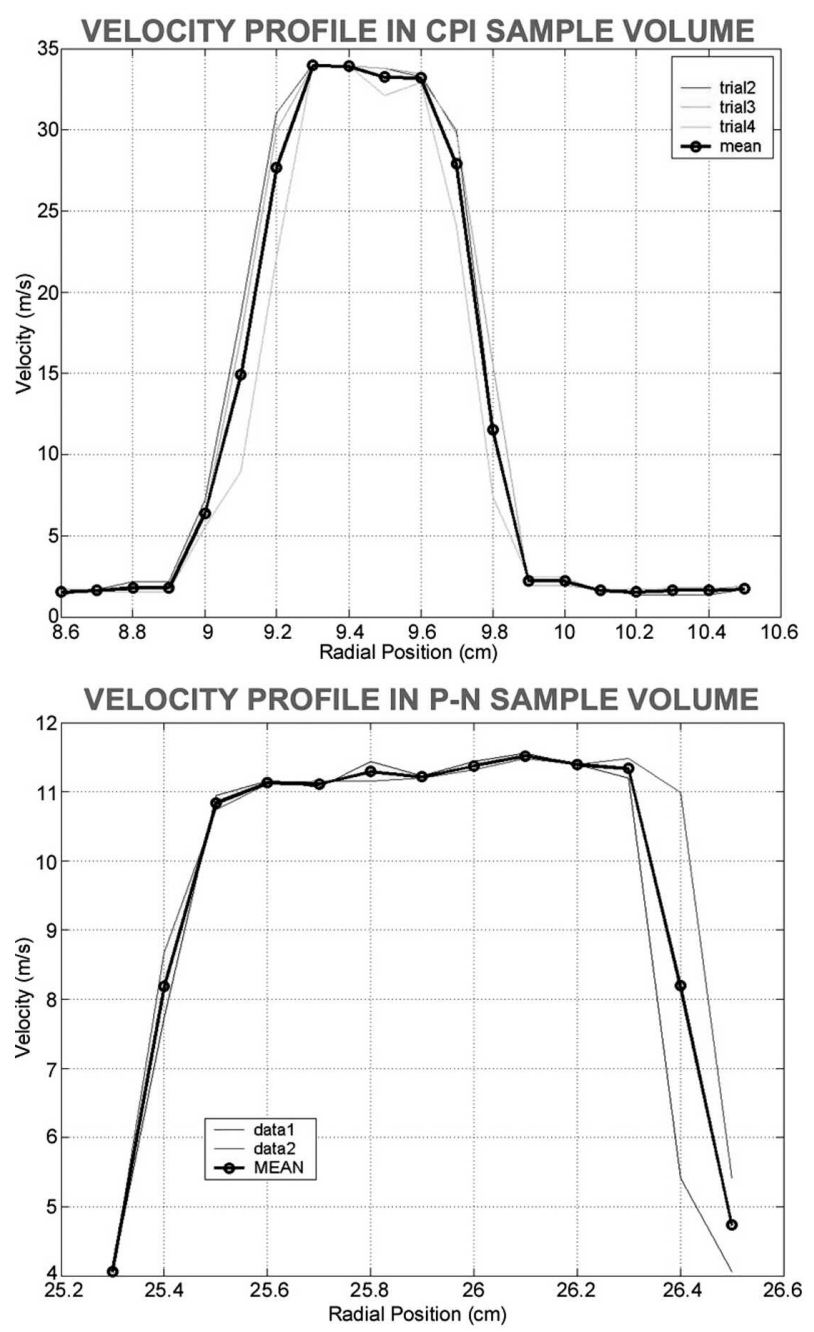

FIG. 2. Velocity profiles measured in the CPI and PN sample volumes with plumbing connecting the two instruments as shown in Fig. 1.

pixel in the CCD camera array has an equivalent size in the sample area of $2.3 \mu \mathrm{m}$, so particles of sizes from approximately $10 \mu \mathrm{m}$ to $2 \mathrm{~mm}$ are imaged. The shadow depth of each pixel can be expressed in up to 256 gray levels and the refresh rate of the CCD camera is $40 \mathrm{~Hz}$. A video-processing software routine identifies and sizes particles imaged on the digital camera, saving only the regions around each image. The PDS system continues to count particles while the digital camera is busy downloading images.

The sample area of the PDS $(2.36 \mathrm{~mm} \times 2.36 \mathrm{~mm} \times$ 0.707 ) times the flow rate shown in Fig. 2 results in a volumetric CPI sample rate of $0.13 \mathrm{~L} \mathrm{~s}^{-1}$, and this is the sample rate used to compute particle concentrations presented in this work. However, it was observed that the actual sample rate appeared to vary with ambient wind speed and orientation of the instruments. The

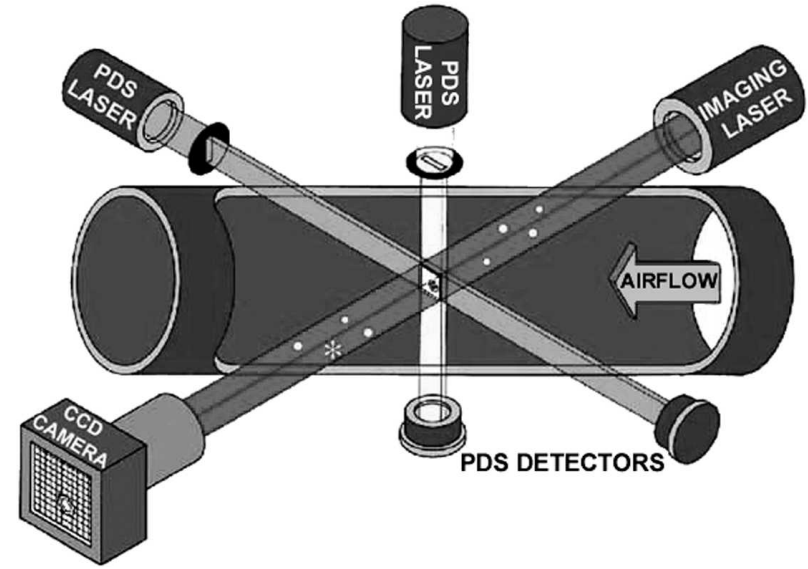

FIG. 3. Schematic drawing showing the electro-optical configuration of the CPI.

variability was mostly due to gravitation settling that occurred when there were larger particles present. This was determined qualitatively by moving the orientation of a CPI, measuring crystal concentration, and returning the CPI to its original position. However, the variability probably did not influence correlations between the CPI and PN measurements, because the two instruments were plumbed together (Fig. 1). Because there was no way to make quantitative measurements of the uncertainty in particle flow rate, we choose not to quote uncertainties in ice crystal concentration measurements. The CPIs were generally operated for approximately $12-18 \mathrm{~h}^{-1 a y}{ }^{-1}$, unless an instrument was shut down because of electrical outages or other interruptions at SPS.

The main advantage of the CPI, when compared with collecting ice crystals on glass slides, is that it records images at a high rate (up to several tens per second) and can run unattended, producing a very large dataset in a relatively short period of time. In addition, CPI images are processed using software that automatically determines crystal type.

The optical configuration of the PN is shown in Fig. 4. The ice crystals are drawn through the volume-scattering chamber and intersect a collimated laser beam (operating at a wavelength of $0.8 \mu \mathrm{m}$ ) near the focal point of a parabolic mirror. The scattered intensities are measured at scattering angles from approximately $5^{\circ}$ to $169^{\circ}$ by two rows of photodiodes located in the upper and lower parts of a circular array (see Fig. 4). Therefore, the PN provides scattering phase functions, also called angular scattering intensities (ASIs) by Shcherbakov et al. (2006), as a two-dimensional scattering pattern defined by the scattering angle $\theta$ and by the azimuthal angle $\varphi$. Accordingly, the notations for 


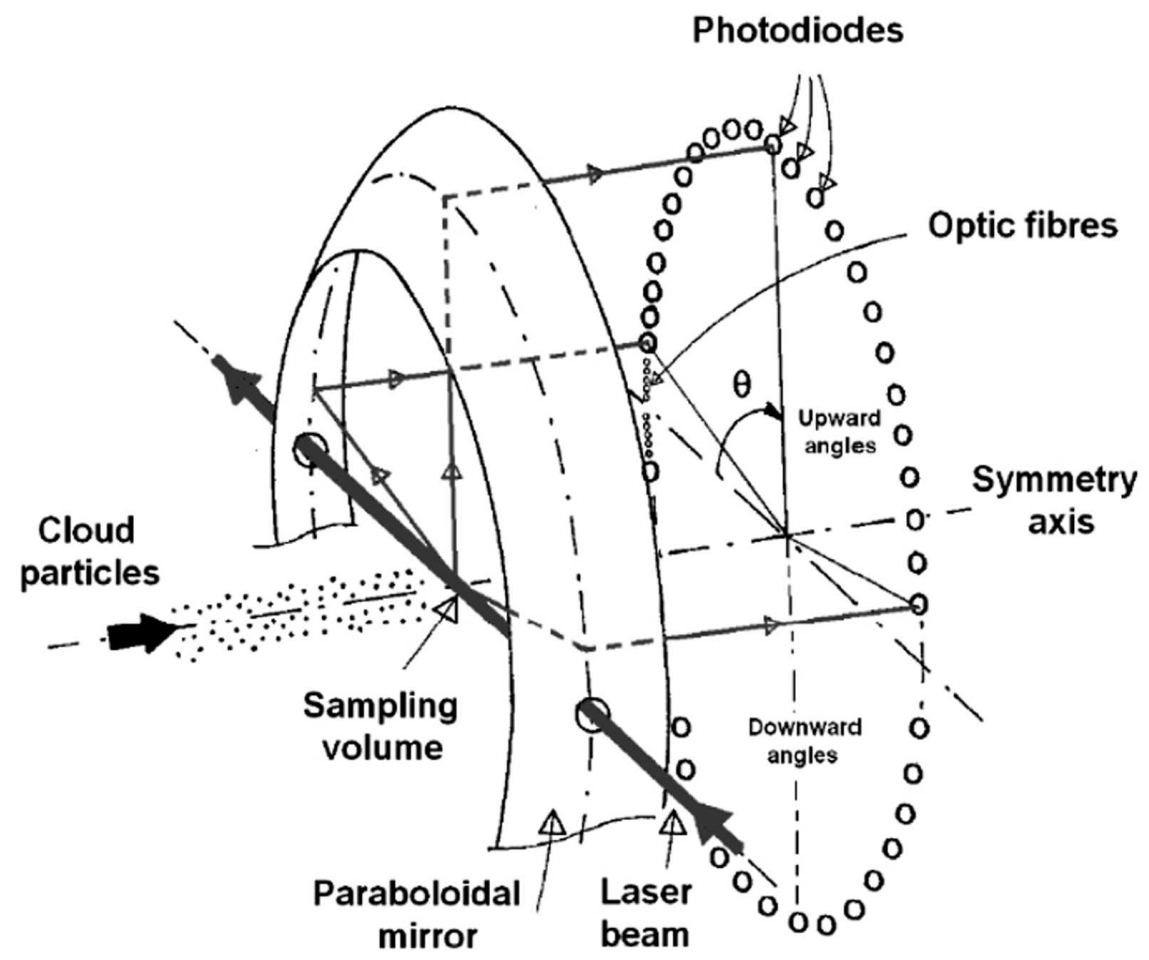

FIG. 4. Schematic drawing showing the optical configuration of the LaMP polar nephelometer.

"upward" and "downward" angles are used to indicate the dependence on the azimuthal angle of ASIs. Table 1 summarizes the scattering angles and the accuracies of the measured intensities.

Scattering phase functions related to an ensemble of randomly oriented ice particles do not depend on the azimuthal angle. In this case, ASIs measured at the upward and downward angles are identical and the scattering properties can be described between $5^{\circ}$ and $169^{\circ}$ (see, e.g., Auriol et al. 2001). On the contrary, for single ice crystal sampling, the upward and downward ASIs mostly have different magnitude and distribution over scattering angles, and depend on the orientation of the ice crystal in the sampling volume. The dataacquisition system of the PN provides a continuous sampling volume by integrating the measured signals of each detector at a selected period. The sample volume $v$ is determined by multiplying the sampling area (10mm-long and 5-mm-diameter beam) by the airspeed (approximately $12 \mathrm{~m} \mathrm{~s}^{-1}$ ), that is, $5 \mathrm{~cm}^{3}$ for the acquisition frequency of $100 \mathrm{~Hz}$, resulting in a sample rate of $0.6 \mathrm{~L} \mathrm{~s}^{-1}$.

The sensitivity of the ASI measurements with low signal-to-noise ratios was significantly improved by removing the background signals for each channel. A wavelet denoising technique (e.g., Rao and Bopardikar
1998) was used to eliminate the low-frequency variation of the background signals. In addition, a special routine was used in order to avoid saturation of recorded signals at any angle.

\section{Data collection}

\section{a. Crystal habit classification}

A total of 721572 CPI images of ice crystals $>50 \mu \mathrm{m}$ in maximum dimension ${ }^{1}$ from the period of $1-8$ February 2001 were placed into categories using an automatic crystal habit classification program. The automatic crystal habit classification program used several attributes that are routinely computed by CPIview software for each CPI image. The attributes include maximum particle image length $L$, maximum width $W$ that is transverse to the maximum length chord, projected area $A$, perimeter $P$, focus value (i.e., how well the crystal is in focus), aspect ratio, roundness, and more sophisticated derivatives, such as radial harmonics (the Fourier transform of consecutive radii drawn from the particle centroid). Several of these attributes are used

\footnotetext{
${ }^{1}$ Unless otherwise noted, all references to size measurements in this paper refer to maximum image dimension as determined by CPIview software.
} 
TABLE 1. Channel numbers, corresponding scattering angles relative to the forward-pointing axis of the laser, and accuracies measured by the PN. The dots in the OK column indicate the available channels. The left part and right part of the table relate to the upward-scattering and downward-scattering angles, respectively.

\begin{tabular}{|c|c|c|c|c|c|c|c|}
\hline \multicolumn{4}{|c|}{ Upward angles } & \multicolumn{4}{|c|}{ Downward angles } \\
\hline Channel No. & Scattering angle $\left({ }^{\circ}\right)$ & OK & Accuracy & Channel No. & Scattering angle $\left(^{\circ}\right)$ & $\mathrm{OK}$ & Accuracy \\
\hline 1 & 4.28 & & & 56 & -3.49 & & \\
\hline 2 & 5.86 & $\bullet$ & $50 \%$ & 55 & -5.07 & & \\
\hline 3 & 7.44 & $\bullet$ & $50 \%$ & 54 & -6.65 & & \\
\hline 4 & 9.02 & $\bullet$ & $50 \%$ & 53 & -8.23 & & \\
\hline 5 & 10.6 & $\bullet$ & $50 \%$ & 52 & -10.6 & & \\
\hline 6 & 15.0 & $\bullet$ & $5 \%$ & 51 & -18.5 & $\bullet$ & $5 \%$ \\
\hline 7 & 22.0 & $\bullet$ & $5 \%$ & 50 & -25.5 & $\bullet$ & $3 \%$ \\
\hline 8 & 29.0 & $\bullet$ & $3 \%$ & 49 & -32.5 & & \\
\hline 9 & 36.0 & $\bullet$ & $3 \%$ & 48 & -39.5 & $\bullet$ & $3 \%$ \\
\hline 10 & 43.0 & $\bullet$ & $3 \%$ & 47 & -46.5 & $\bullet$ & $3 \%$ \\
\hline 11 & 50.0 & $\bullet$ & $3 \%$ & 46 & -53.5 & $\bullet$ & $3 \%$ \\
\hline 12 & 57.0 & $\bullet$ & $3 \%$ & 45 & -60.5 & & \\
\hline 13 & 64.0 & $\bullet$ & $3 \%$ & 44 & -67.5 & & \\
\hline 14 & 71.0 & $\bullet$ & $3 \%$ & 43 & -74.5 & & \\
\hline 15 & 78.0 & - & $3 \%$ & 42 & -81.5 & & \\
\hline 16 & 85.0 & $\bullet$ & $3 \%$ & 41 & -88.5 & & \\
\hline 17 & 92.0 & $\bullet$ & $3 \%$ & 40 & -95.5 & & \\
\hline 18 & 99.0 & $\bullet$ & $3 \%$ & 39 & -102.5 & & \\
\hline 19 & 106.0 & $\bullet$ & $3 \%$ & 38 & -109.5 & • & $3 \%$ \\
\hline 20 & 113.0 & $\bullet$ & $3 \%$ & 37 & -116.5 & & \\
\hline 21 & 120.0 & $\bullet$ & $3 \%$ & 36 & -123.5 & & \\
\hline 22 & 127.0 & $\bullet$ & $3 \%$ & 35 & -130.5 & & \\
\hline 23 & 134.0 & & & 34 & -137.5 & $\bullet$ & $5 \%$ \\
\hline 24 & 141.0 & $\bullet$ & $5 \%$ & 33 & -144.5 & • & $10 \%$ \\
\hline 25 & 148.0 & $\bullet$ & $10 \%$ & 32 & -151.5 & $\bullet$ & $15 \%$ \\
\hline 26 & 155.0 & • & $20 \%$ & 31 & -158.5 & & \\
\hline 27 & 162.0 & - & $30 \%$ & 30 & -165.5 & & \\
\hline 28 & 169.0 & $\bullet$ & $50 \%$ & 29 & -172.5 & & \\
\hline
\end{tabular}

in conjunction to automatically sort the particle images into ice crystal shape categories. Descriptions of the specific algorithms used to classify CPI images into crystal habits are found in the appendix.

On occasion, the automatic crystal classification program could not distinguish reliably between crystal types (e.g., distinguishing irregulars from thick plates; columns from single bullets). When this occurred, which was approximately $20 \%$ of the dataset, the crystals were visually classified by examining a representative subset. Thus, the overall error of $<10 \%$ is based on visual examination of approximately 50000 of the processed images that are representative of the entire dataset. However, it should be kept in mind that even visual classification of crystal habits is subjective.

During the 1-8 February period, the surface temperature at SPS ranged from $-30^{\circ}$ to $-39^{\circ} \mathrm{C}$. Of the total, 180023 crystal images smaller than $50 \mu \mathrm{m}$ were eliminated, because the program could not reliably distinguish between small spheroids, irregular shapes, and small plates. Figure 5 shows a histogram of the percentage breakdown of the remaining 721572 crys- tals $>50 \mu \mathrm{m}$. The histogram is shown as a function of particle number, area, and mass for eight habit categories. Figure 6 shows typical examples of CPIs classified in Fig. 5, along with an example of CPIs smaller than $50 \mu \mathrm{m}$ that were excluded from the histogram. Crystals classified as short columns/thick plates (C1g in the Magono and Lee 1966 classification), columns (C1e and C1f), and plates (P1a) are also labeled "diamond dust" in Fig. 5, resulting from their sparkly appearance in sunlight. As discussed later, diamond dust is typically observed under very thin, high clouds that are penetrated by the sun's rays and often produce optical effects, such as halos and arcs.

Crystals classified as rosette shapes, budding rosettes (rosette shapes with short branches), mixed-habit rosettes, and rosette shapes with side planes fall into a general category we will call rosette shapes. Single bullets were observed rarely and were always associated with rosette shapes or complex crystals. Rosette shapes are polycrystals that are typically formed from rapid freezing of a supercooled water drop or solution drop (Pruppacher and Klett 1997; Bacon et al. 2003). 


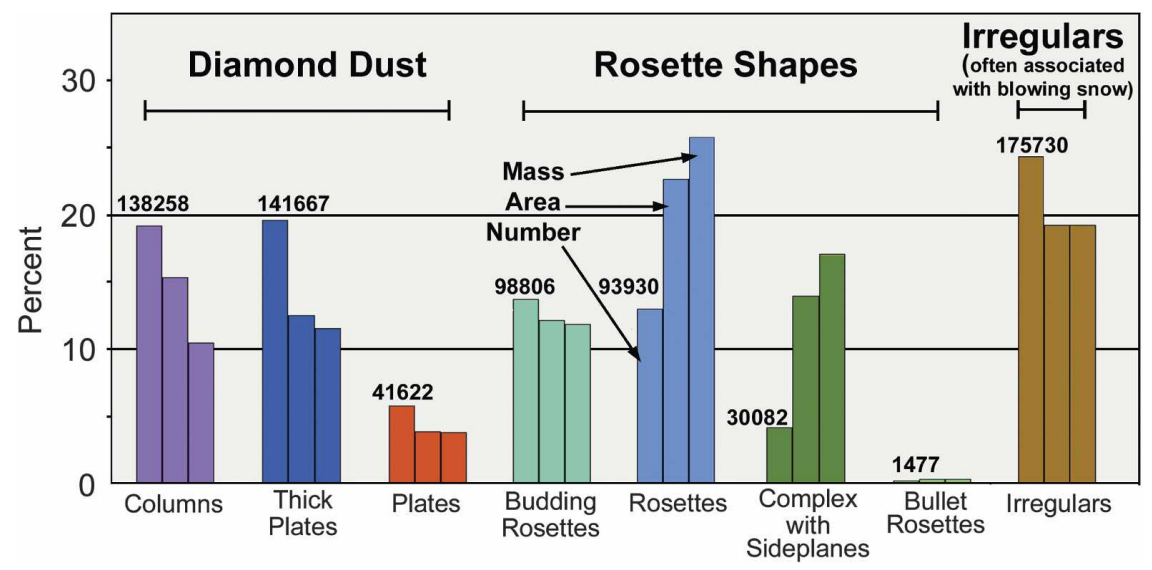

FIG. 5. Histogram of ice crystal habits observed at SPS during the period of 1-8 Feb 2001. The percentage weighted by concentration, area, and mass is shown for each habit category. Columns, thick plates/short columns, and plates are associated with diamond dust. Budding rosettes, rosettes, and complex with side planes are associates with rosette shapes. The total number of crystals of each habit is shown above its category. The total number of ice crystals categorized is 721572 .

In addition to the general classifications of diamond dust and rosette shapes, the other major category shown in Fig. 5 is irregularly shaped crystals. Korolev et al. (1999) found that non-pristine-shaped ice crystals accounted for $>95 \%$ of the shapes observed in Arctic ice clouds. Our observations suggest that nonpristine shapes are not nearly as prevalent in precipitating Antarctic clouds, but contamination from blowing snow makes it impossible to make a quantitative assessment. The irregular shapes observed at SPS were usually small $(<\approx 100 \mu \mathrm{m})$ ice particles. In blowing snow, irregular shapes were observed when there were no precipitating crystals, and irregular crystals were also observed when the wind was too weak to generate blowing snow. The only discernable difference, which is not absolutely distinct, is that the blowing snow irregular shapes generally had more rounded edges (Fig. 6). It was not possible to determine the percentage of blowing snow from precipitating irregular crystals. However, for more than $80 \%$ of the time during 1-8 February 2001 , the wind was in excess of $4 \mathrm{~m} \mathrm{~s}^{-1}$, which was typically the threshold wind speed for generating blowing snow during this period.

When sorted by number, rosette shapes constitute $30 \%$ of the crystals, diamond dust (columns, thick plates and plates) contribute $45 \%$, and irregular shapes are $25 \%$ (which are largely composed of blowing snow). In comparison, W03 found about $1 \%$ rosette shapes, $19 \%$ diamond dust, and $80 \%$ blowing snow. This can likely be attributed to the higher average wind speed in winter. When sorted by area, rosette shapes comprise $50 \%$, diamond dust $30 \%$, and irregular shapes
$20 \%$, as compared with $21 \%, 27 \%$, and $52 \%$, respectively, observed in winter by W03. By mass, our percentages are $57 \%$ rosette shapes, $23 \%$ diamond dust, and $20 \%$ irregular shapes, as compared with $47 \%, 17 \%$, and $36 \%$ observed in winter by W03. Thus, the rosette shapes, while less frequent in occurrence, accounted for the majority of the area and mass of ice crystals observed at SPS during 1-8 February 2001, which agrees with results from the five summer SPS observations by Ohtake (1978) and Ohtake and Yogi (1979). In comparison, W03 found that rosette shapes comprised 47\% of the mass, but only $1 \%$ of the number concentration in winter. Blowing snow was much more predominant in winter, however, our study is only representative of 9 days, so our percentages may not be representative of the entire austral summer.

A time series showing the concentration and habits of ice crystals $>50 \mu \mathrm{m}$ observed at SPS when the CPI was operating from 1 to 8 February 2001 is shown in Fig. 7. During the observation period, the environmental conditions associated with generation of diamond dust were, for the most part, exclusive of the conditions that supported production of rosette shapes. Typically, rosette shapes were observed when there was a broken or overcast layer within approximately $1 \mathrm{~km}$ of the surface. Because polycrystalline crystals, such as rosette shapes, are thought to form when a supercooled water drop freezes rapidly, it is likely that these clouds contained water drops. Support for this premise at SPS comes from additional observations conducted by Mahesh et al. (2001) and Walden et al. (2005). They observed supercooled liquid water drops 


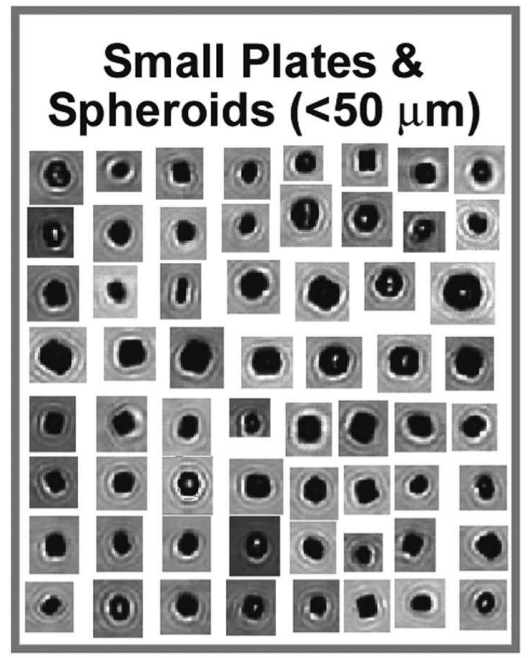

\section{Budding Rosettes}
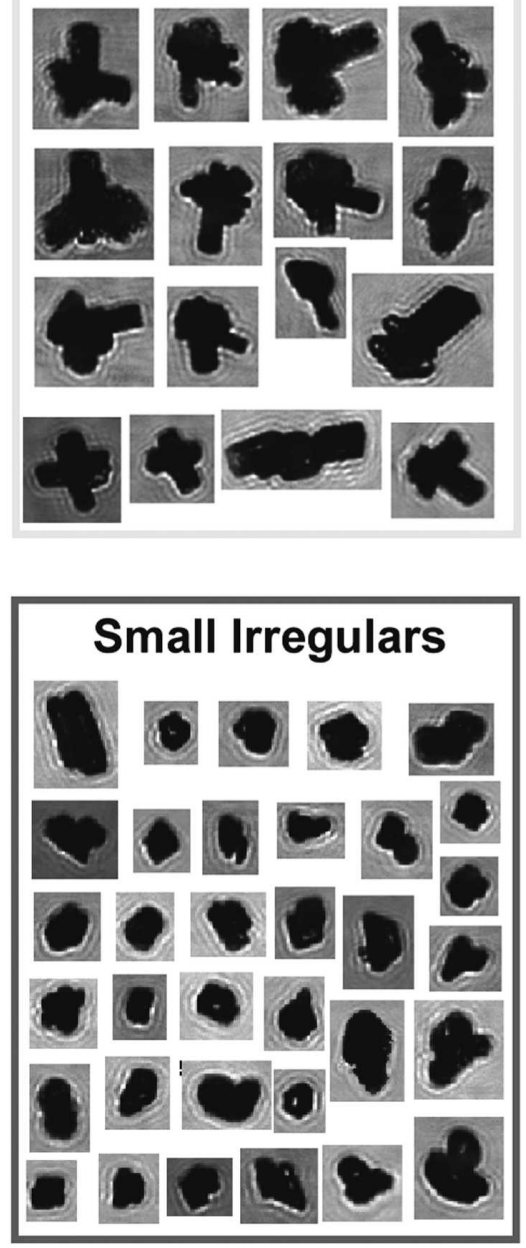
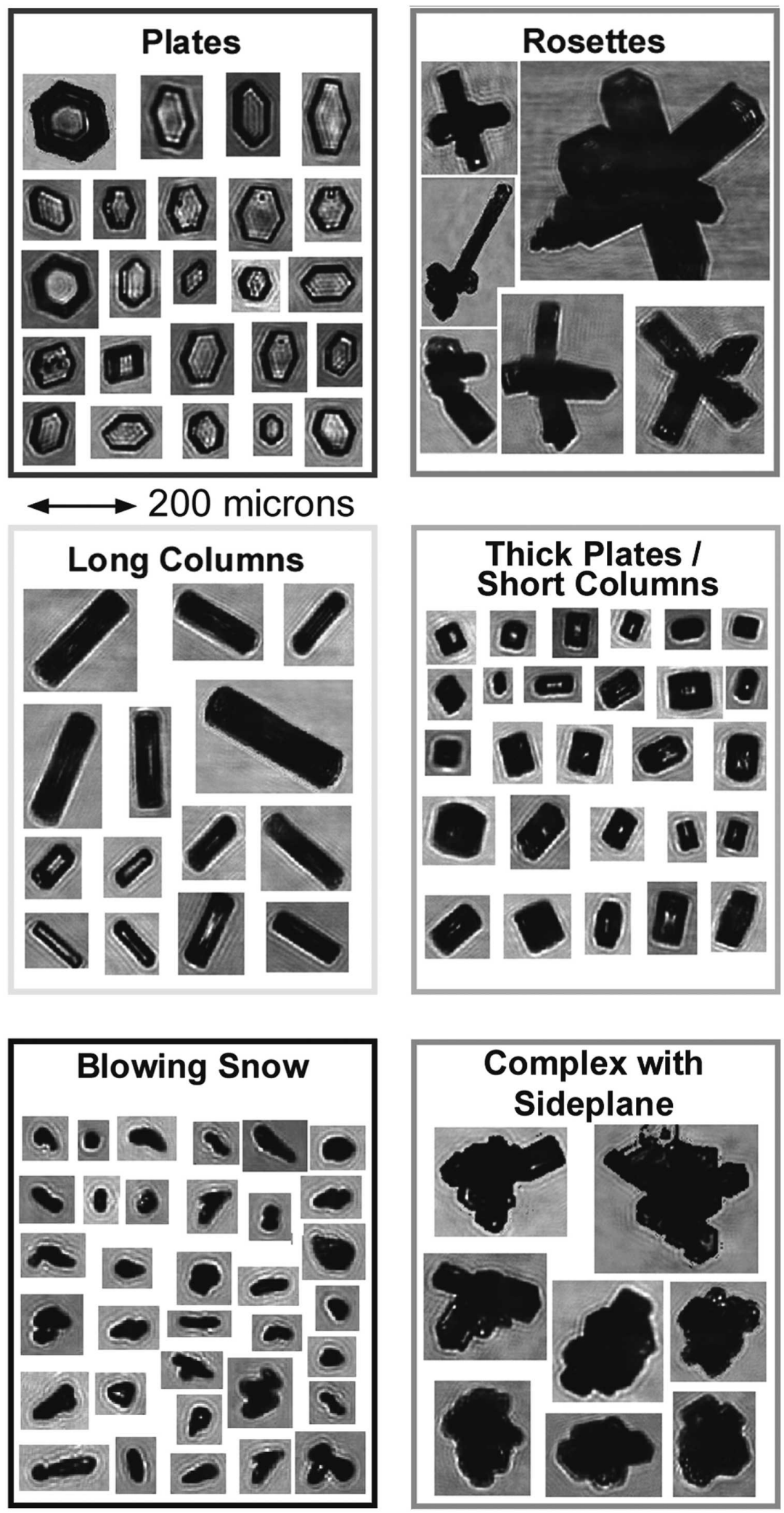

FIG. 6. Examples of CPI images of ice crystals sorted into habit categories. 

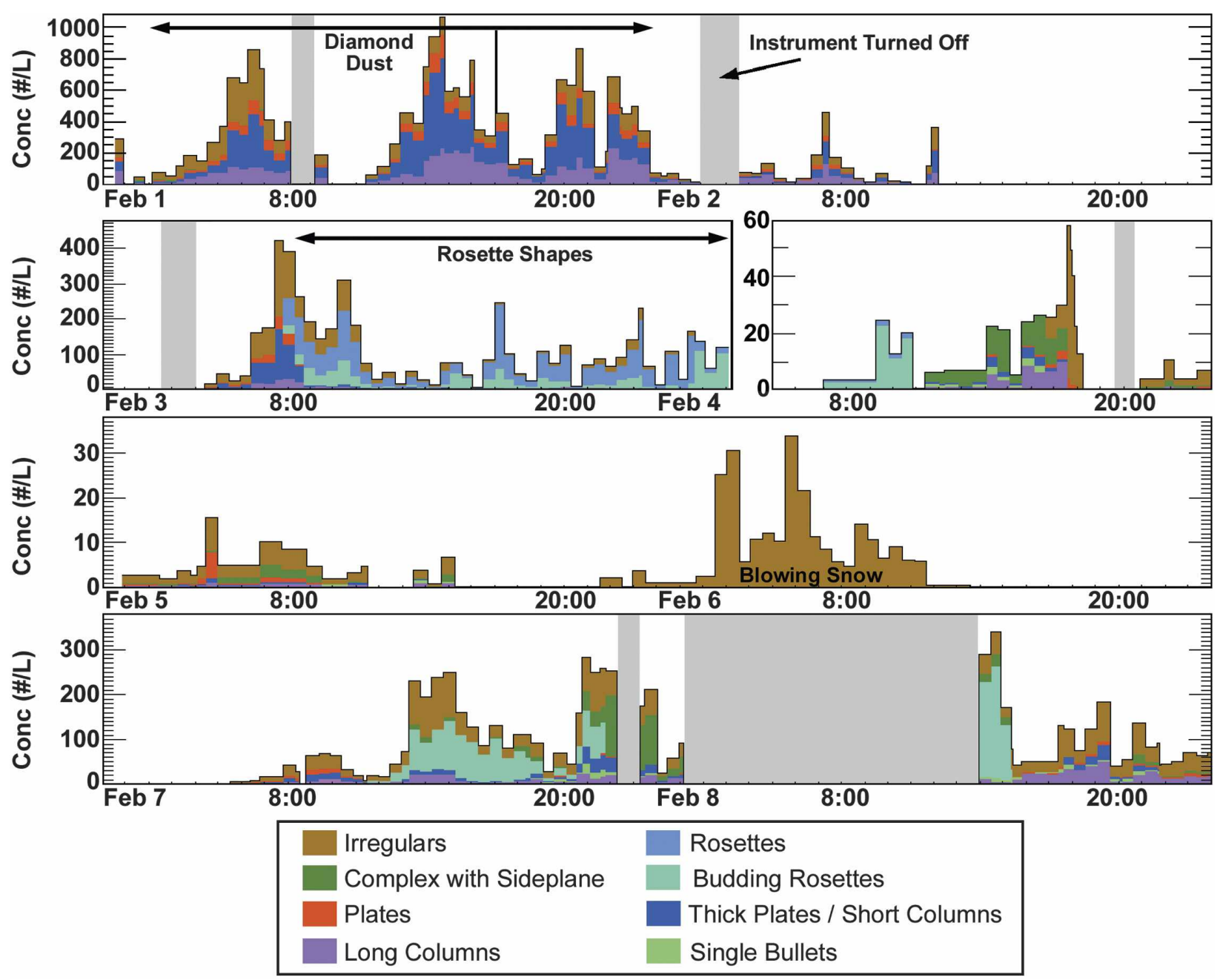

FIG. 7. Time series showing CPI measurements of 721572 ice crystals $>50 \mu \mathrm{m}$ observed at SPS during the period of 1-8 Feb 2001. Total ice crystal concentration is shown on the ordinate and ice crystal habits are color coded. Periods with diamond dust on 1 February, rosette-shaped ice crystals on 3 February, blowing snow on 6 February, and complex crystals with side planes are shown in more detail in Figs. 8 and 9.

in the temperature range from $-28^{\circ}$ to $-35^{\circ} \mathrm{C}$, using a hydrometeor videosonde (HYVIS) balloon-borne sonde, which records video images of cloud particles (Orikasa and Murakami 1997). Diamond dust was typically observed when there were thin clouds, often with atmospheric optics and the sun visible through the clouds. Generally, very few or no crystals were observed when there were no clouds, which is in general agreement with the SPS summertime findings from other investigators (see Bromwich 1988).

\section{b. Relationship between crystal habits and particle size distributions}

Figure 8 shows an example on 1 February 2001 during a period when there was diamond dust, and another example on 3 February 2001 when there were rosette shapes. For reference, each of the periods is also highlighted in Fig. 7. The cloud cover, also shown on Fig. 8, was relatively thin and high (4000 ft, $1220 \mathrm{~m} \mathrm{AGL)} \mathrm{on}$ 1 February, and low (1000 ft, $305 \mathrm{~m}$ AGL) and overcast on 3 February. The cloud cover is derived from routine hourly observations taken by National Oceanic and Atmospheric Administration (NOAA) meteorologists at SPS; and when an hourly observation is missing, the data are supplemented by observations from SPEC scientists and measurements from the National Aeronautics and Space Administration (NASA) vertically pointing micropulse lidar (Campbell et al. 2002), based at the NOAA Atmospheric Research Observatory (ARO) at SPS. Below the cloud cover, Fig. 8 shows examples of CPI images observed in each of the two regimes. The diamond dust is composed of mostly pristine crystals, 
February 1
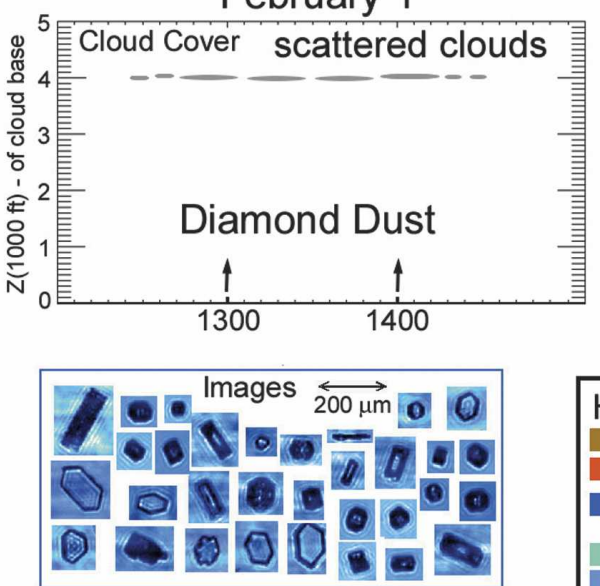

February 3
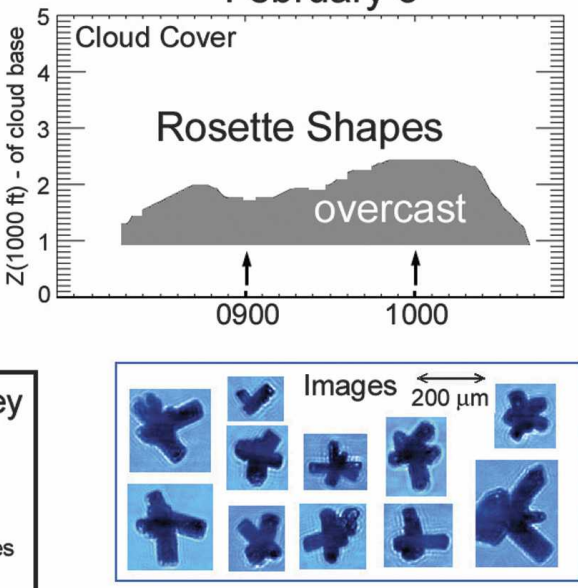

Budding Rosettes

Rosettes

Long Columns
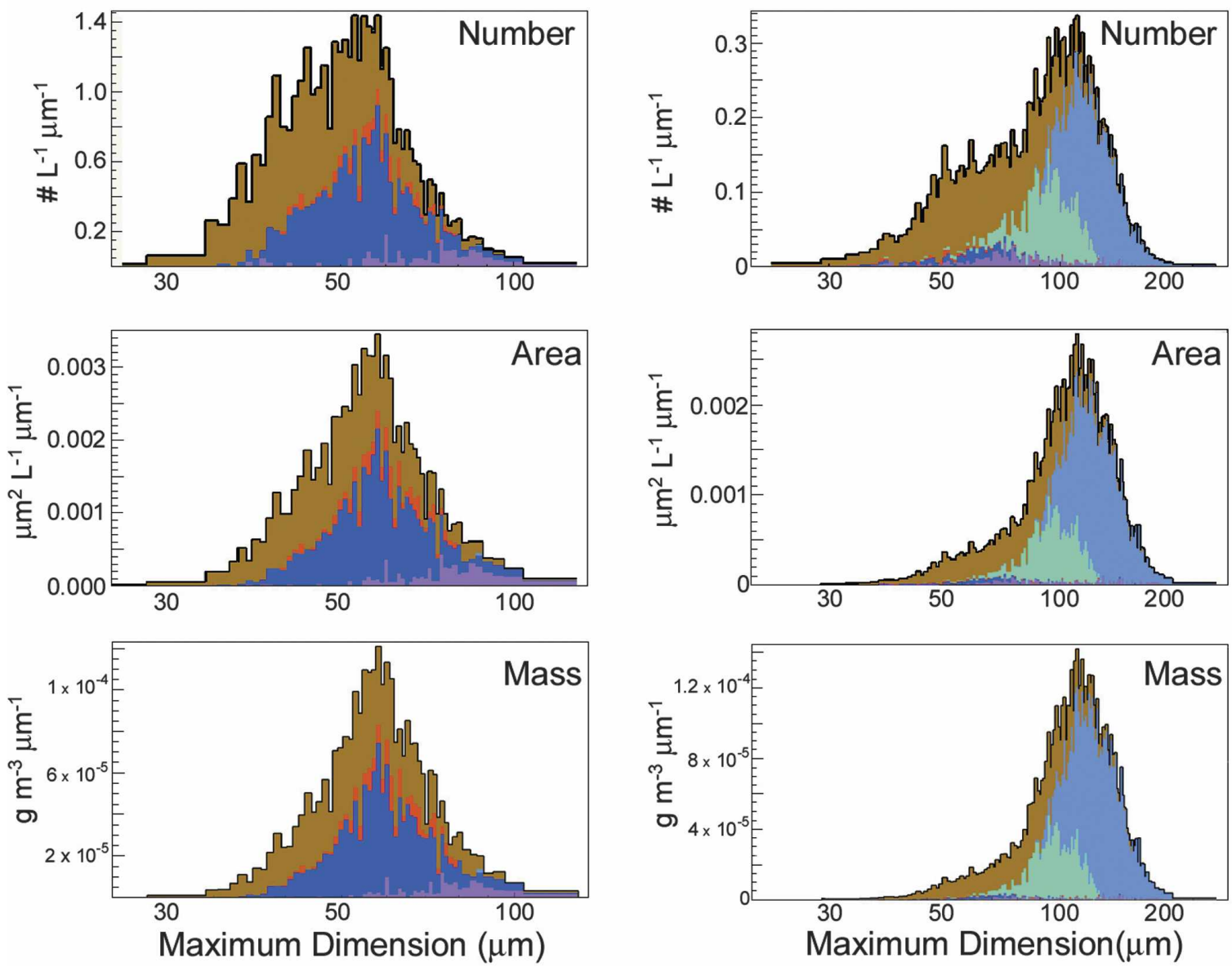

FIG. 8. Example of time periods (shown in Fig. 7) when (left) diamond dust and (right) rosette shapes are prevalent. Elevation and type of cloud cover is shown in the top panels, examples of CPI images are shown below cloud cover, and PSDs weighted by concentration, area, and mass, and color coded to show crystal habits are shown in the bottom three panels.

consisting of mostly thick plates/short columns, long columns, and clear plates.

Figure 8 also shows particle size distributions (PSDs), including crystals $<50 \mu \mathrm{m}$, weighted by concentration, area $A$ and mass $M$. Figure 9 shows PSDs for blowing snow and complex crystals in a format similar to that in Fig. 8. The area calculation in Figs. 8 and 9 is of imageprojected area $A_{\mathrm{pi}}$, which is simply the number of pixels 
February 6
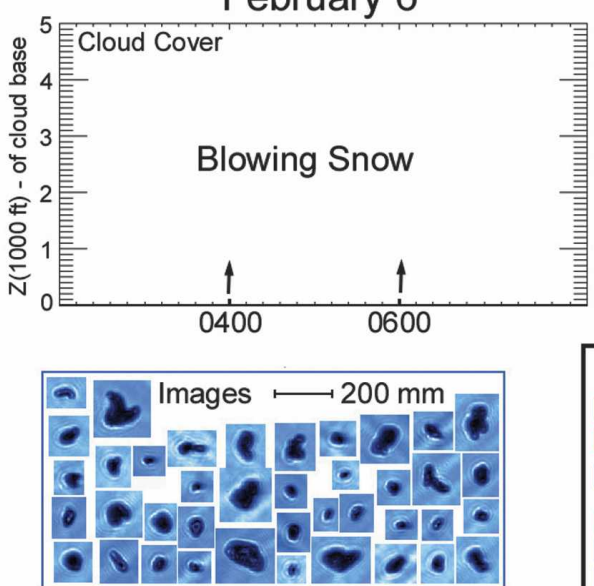

February 7
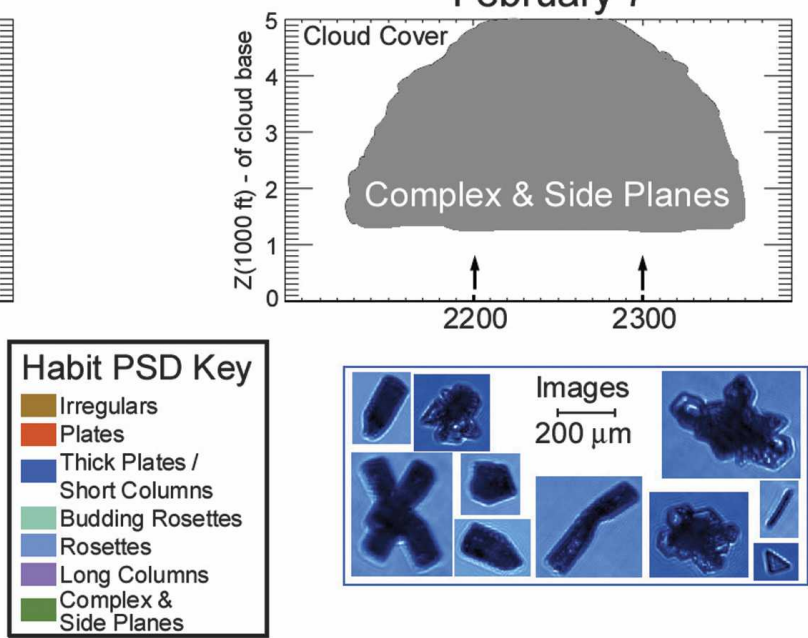
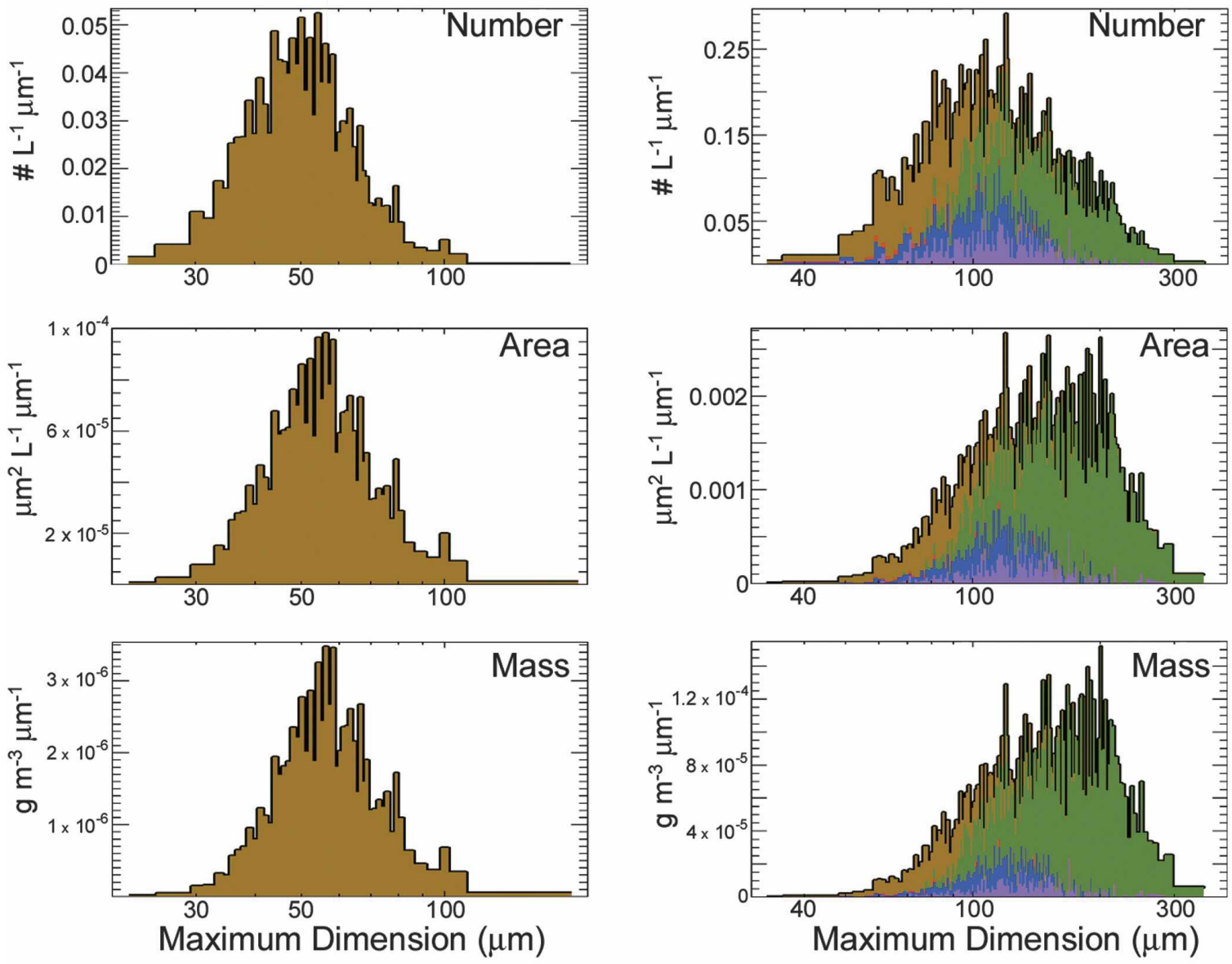

FIG. 9. As in Fig. 8, except data are for blowing snow and complex crystals.

contained within the image perimeter. Particle mass is computed using a technique described by Baker and Lawson (2006b). The technique combines $L, W, A$, and $P$ into a single parameter $X=2 A W(L+W) / P$ and inserts the parameter into the relationship $M=a X^{b}$.
The constants $a$ and $b$ are determined by a least squares fit to measurements from a set of crystal images and melted drops previously collected by Mitchell et al. (1990). Baker and Lawson (2006b) show that, when applied to the Mitchell et al. (1990) dataset, the new 
technique has a $50 \%$ reduction in rms error of measured mass, when compared with $X=L$, which is the technique used by Mitchell et al. (1990). Because the Baker and Lawson (2006b) analysis was based on the Mitchell et al. (1990) dataset that was collected at the surface in the Sierra Nevada, this dataset may not be representative of crystal types found falling from clouds at SPS. Therefore, errors in mass determination from CPIs may (or may not) be large, but there is no way to reliably estimate the uncertainty, and so no attempt is made to state uncertainties in particle mass or ice water content shown in this paper.

The PSDs in Figs. 8 and 9 are color coded to show the relationship between crystal habits and size. As shown in Fig. 6, crystals $<50 \mu \mathrm{m}$ generally look like small plates and spheroids. In Figs. 8 and 9, these particles have been lumped together with the irregular shapes. It is not possible to reliably sort crystals $<50 \mu \mathrm{m}$ into categories using CPIview-automated classification software. However, visual inspection of the images shows that when diamond dust is observed, there is a much higher percentage of small plates, and when rosette shapes are observed, there is a much higher percentage of small spheroids. This is expected (Pruppacher and Klett 1997; Bacon et al. 2003), because diamond dust (i.e., hexagonal shape) is expected to grow via vapor diffusion after heterogeneous nucleation, and rosettes are generally formed by rapid freezing of a supercooled drop (i.e., spheroidal shape).

The PSDs in Fig. 8 show that the diamond dust extends out to sizes of approximately $150 \mu \mathrm{m}$ and is dominated by thick plates with some columns and plates, and that rosette shapes extend out to approximately 250 $\mu \mathrm{m}$. These larger sizes may be due to their formation and growth in a water-saturated environment (although growth may also occur in an ice-saturated environment below cloud). From 50 to $80 \mu \mathrm{m}$, the rosette-shaped PSD consists of mostly irregular shapes, along with a small percentage of thick plates/short and long columns. From 80 to approximately $130 \mu \mathrm{m}$, budding rosettes dominate the PSD, and rosette shapes predominate from 130 to $250 \mu \mathrm{m}$. Approximately $80 \%$ of the mass of ice crystals $>80 \mu \mathrm{m}$ consists of rosette shapes. (including budding rosettes).

Figure 9 shows examples of color-coded PSDs in the same format as Fig. 8. The data in Fig. 9 were collected in blowing snow from 0400 to 0600 UTC 6 February 2001, and from 2200 to 2300 UTC 7 February 2001 when there were mostly complex crystals with side plane, along with some rosette shapes, single bullets, columns, and plates. Each of these time periods is also highlighted in Fig. 7. There were no clouds during the period with blowing snow on 6 February, and there were relatively low and thick, from $1500(457 \mathrm{~m})$ to $\sim 6000(1830 \mathrm{~m}) \mathrm{ft}$ AGL, clouds on 7 February, similar to, but perhaps thicker than, clouds typically observed when rosettes are the dominant habit.

The examples of CPI images in Fig. 9 show that the complex crystals are often somewhat rosette shaped with side planes, similar to shapes observed in the laboratory by Bailey and Hallett (2004) at temperatures ranging from $-30^{\circ}$ to $-40^{\circ} \mathrm{C}$. They found that pure bullet rosettes, that is, bullet rosettes with columnar arms and no side planes, only grew at temperatures $<\approx-40^{\circ} \mathrm{C}$. However, the atmosphere at SPS on 7 February was warmer than $-40^{\circ} \mathrm{C}$ from the surface to 447 $\mathrm{hPa}(5850 \mathrm{~m} \mathrm{msl})$, and there were no clouds reported above approximately $600 \mathrm{hPa}$. As can be seen from Figs. 7 and 9, the large majority of the crystal habits during the time period from 2100 to 0000 UTC were complex, with side planes; however, pure bullet rosettes were also observed on occasion. Pure bullet rosettes were observed in small $(<5 \%)$ proportions on other days when the cloud temperature was $>-40^{\circ} \mathrm{C}$, suggesting that while the laboratory result may indicate a valid temperature trend, it is not an absolute condition. Supporting evidence for rare observations of pure bullet rosettes at temperatures $>-40^{\circ} \mathrm{C}$ in wave clouds is also shown by Baker and Lawson (2006a).

The color-coded PSD shown for the complex crystals has side planes that extend out to $400 \mu \mathrm{m}$, which is larger than either diamond dust or rosette shapes. On other days, complex crystals with side planes were occasionally observed to have sizes as large as $600-800$ $\mu \mathrm{m}$. Unlike the diamond dust and rosette-shaped colorcoded PSDs, complex crystals dominate the PSDs at sizes $>\approx 100 \mu \mathrm{m}$. This correlates with visual observations that complex crystals were typically observed to be larger than crystals in the other categories and occurred in relatively low concentrations.

Single bullets were also observed during the period on 7 February when there were predominantly complex crystals with side planes and some rosette shapes. Some examples of CPI images of single bullets are shown in Fig. 9. It could not be determined if the single bullets resulted from breakage of bullet rosettes, or if they grew as single bullets.

The blowing snow shown in Fig. 9 is composed of almost entirely irregular shapes with sizes $<100 \mu \mathrm{m}$. The peak in all three (number, area, and mass) size distributions is $55 \mu \mathrm{m}$, which indicates that this is a characteristic mode of the size distribution. The threshold wind speed for blowing snow at SPS is a function of the surface snow condition, and therefore is not consistent. There were not enough events of blowing snow with cloudless skies during the observation periods at 

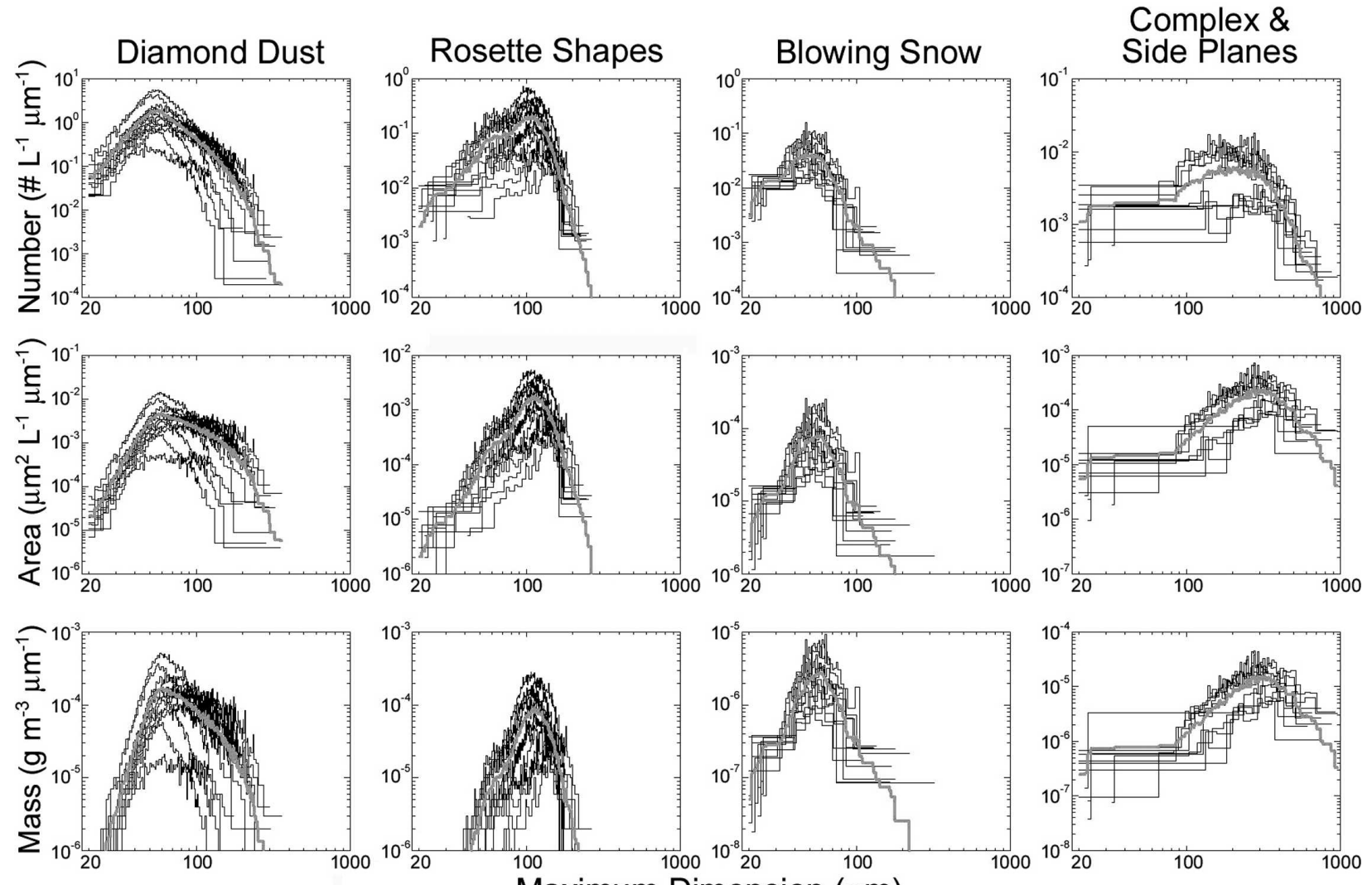

FIG. 10. Individual particle size distributions (black lines) for 30-min intervals and average PSD (gray lines) during periods with (from left to right) sustained periods of diamond dust, rosette shapes, blowing snow, and complex crystals.

SPS to correlate PSDs with either snow conditions, observation level, or wind speeds. However, one may assume that the shape and mode of the PSD would change with these parameters.

As shown in Fig. 7, diamond dust, rosette shapes, and blowing snow were the dominant crystal habits for several hours during the observations taken from 1 to 8 February 2001. This consistency in crystal type during these periods provides enough measurements to construct PSDs for discrete time periods and compute an average for the entire time period. Figure 10 shows discrete and average PSDs weighted by concentration, area, and mass during periods of diamond dust, rosette shapes, blowing snow, and complex crystals. In general, sizes of crystals increase, starting with blowing snow being the smallest, then diamond dust, rosettes, and complex crystals being by far the largest, extending in size out to $1 \mathrm{~mm}$ (mostly observed when the CPI was oriented vertically).

\section{c. Equivalent radius}

W03 expressed PSDs of their ice crystal data collected at SPS in terms of equivalent radius $r_{\mathrm{VA}}=3 \mathrm{VI}$
$A_{\mathrm{SI}}$, where $V$ is particle volume and $A_{\mathrm{SI}}$ is the total surface area, including the surface area contained internally if the crystal contains parts that are hollow. The formulation of $r_{\mathrm{VA}}$ has as its basis the work performed by Grenfell and Warren (1999), who expressed the radiative properties of ice particles by a collection of independent spheres. For the sake of comparison with the work of W03, we compute PSDs as a function of $r_{\mathrm{VA}}$ and show the results in Fig. 11.

W03 did a manual analysis of the volume and surface area to estimate three-dimensionality and internal hollowness of ice particles. In our work, we use the technique described by Baker and Lawson (2006b) to compute $V=M / \rho_{\text {ice }}$, where $\rho_{\text {ice }}=0.918$. Schmitt and Heymsfield (2005) did theoretical calculations and analyzed CPI data to determine a generalized formula for estimating total particle surface area from projected area, which is computed using CPIview software. Adapting Eq. (5) from Schmitt and Heymsfield (2005), total particle surface area is estimated from $A_{\mathrm{SI}}=$ $5.6\left(4 A_{\mathrm{PI}}{ }^{-0.6} / \pi L^{2}\right)^{-0.6}$, where $A_{\mathrm{PI}}$ is particle projected area and $L$ is maximum dimension.

Table 2 compares the results of the means of $r_{\mathrm{VA}}$ for 

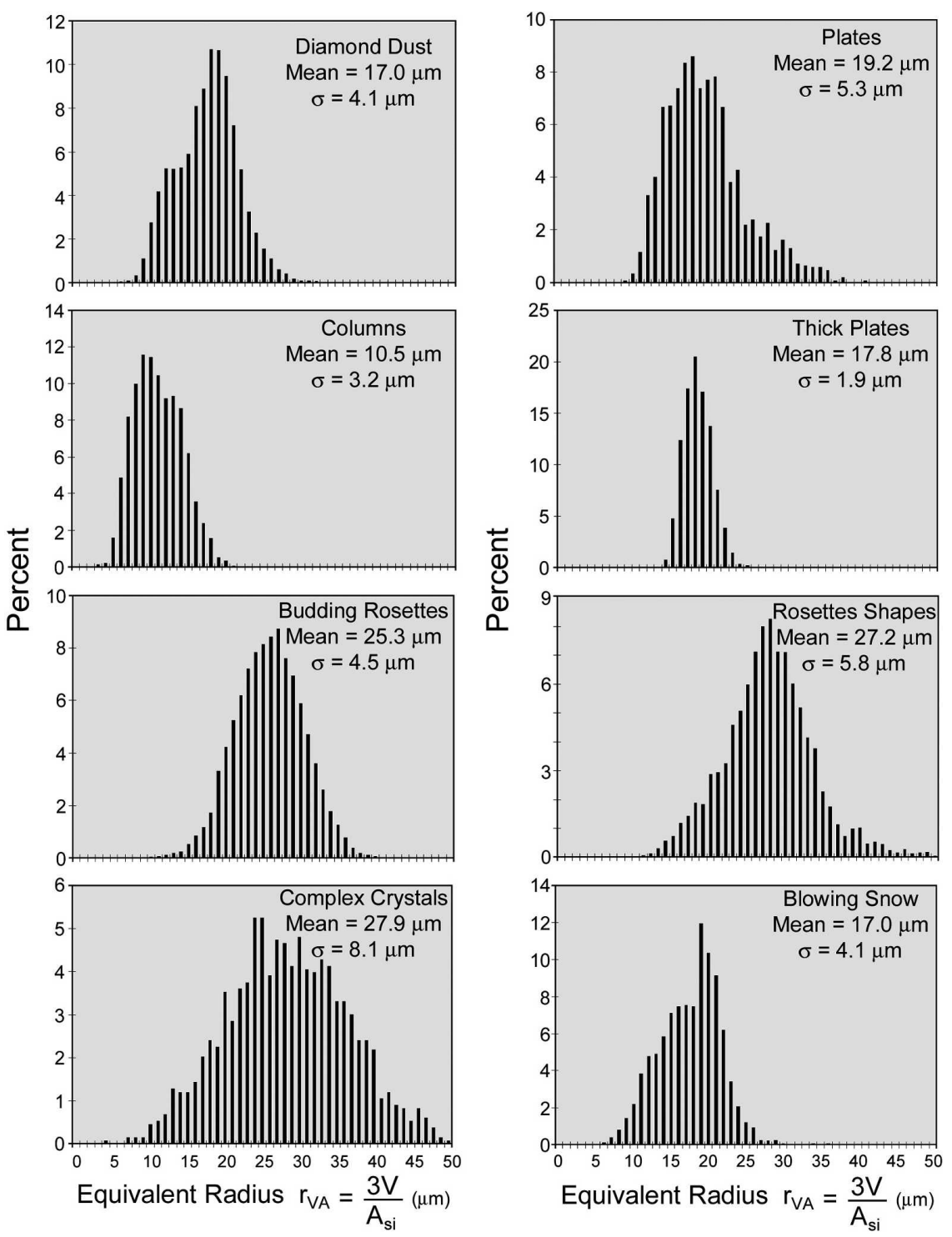

FIG. 11. Histograms showing size distributions of various ice crystal habits as a function of equivalent radius.

various crystal types estimated by W03, and uses the technique described above for data collected during our study. Results from our study were obtained from measurements taken from regions when the automatic classification program correctly identified $>90 \%$ of the crystal habits. The data in Table 2 show relatively good agreement between W03 and our (SPEC) results. W03 measured a mean $r_{\mathrm{VA}}$ for wintertime diamond dust at $12.2 \mu \mathrm{m}$ and in summertime $r_{\mathrm{VA}}$ their mean value is 15 $\mu \mathrm{m}$. They also computed a mean $r_{\mathrm{VA}}=17.2 \mu \mathrm{m}$ from Kikuchi and Hogan (1979) summertime diamond dust observations. The value of mean $r_{\mathrm{VA}}=17.0 \mu \mathrm{m}$ computed from SPEC data is close to the Kikuchi and Hogan (1979) value and supports the W03 observations that diamond dust is larger in summer than in winter. The mean $r_{\mathrm{VA}}=10.1 \mu \mathrm{m}$ for solid columns reported by W03 agrees very well with our $r_{\mathrm{VA}}=10.5 \mu \mathrm{m}$ for all columns. The summertime SPEC $r_{\mathrm{VA}}=19.2 \mu \mathrm{m}$ for plates exceeds the W03 $r_{\mathrm{VA}}=15.1 \mu \mathrm{m}$ by about $4 \mu \mathrm{m}$. The $r_{\mathrm{VA}}$ values for SPEC budding rosettes, rosette shapes, and complex crystals are 25.3, 27.2, and 27.9 $\mu \mathrm{m}$, respectively, which agrees well with the $\mathrm{W} 03$ value of $25.2 \mu \mathrm{m}$ for bullet clusters. The largest difference in $r_{\mathrm{VA}}$ is in blowing snow, with the SPEC summer mean of $r_{\mathrm{VA}}=17 \mu \mathrm{m}$ exceeding the W03 wintertime $r_{\mathrm{VA}}=11$ $\mu \mathrm{m}$ by nearly $6 \mu \mathrm{m}$. This is somewhat counterintuitive, because of the higher wind velocities in winter (W03). However, the larger summertime mean equivalent ra- 
TABLE 2. Comparison of mean equivalent radii $(\mu \mathrm{m})$ for various ice crystal habits determined from measurements taken by Walden et al. (2003) (W03) and this study (SPEC).

\begin{tabular}{|c|c|c|c|c|c|c|}
\hline \multirow[b]{3}{*}{ Diamond dust } & \multirow{2}{*}{\multicolumn{3}{|c|}{$\begin{array}{c}\text { SPEC } \\
\text { Summer }\end{array}$}} & \multicolumn{3}{|c|}{ W03 } \\
\hline & & & & \multirow{2}{*}{$\begin{array}{c}\text { Winter } \\
12.1\end{array}$} & \multicolumn{2}{|c|}{ Summer } \\
\hline & 17.0 & & & & 15.0 & 17.2 \\
\hline Columns $^{\mathrm{b}}$ & 10.5 & & & 10.1 & & \\
\hline Plates & 19.2 & & & 15.1 & & \\
\hline Bullet clusters & $25.3^{\mathrm{c}}$ & $27.2^{\mathrm{d}}$ & $27.9^{\mathrm{e}}$ & 25.2 & & \\
\hline Blowing snow & 17.0 & & & 11.0 & & \\
\hline
\end{tabular}

a Kikuchi and Hogan (1979), data processed by W03.

${ }^{\mathrm{b}}$ W03: solid columns; SPEC: all columns.

${ }^{\mathrm{c}}$ Budding rosettes.

${ }^{\mathrm{d}}$ Rosette shapes.

e Complex (rosette) crystals.

dius for blowing snow may also be due to the overall larger particle sizes in summer as compared with winter.

It is interesting to note that when the Schmitt and Heymsfield (2005) habit-specific formulas are used for (hollow) columns, plates, and rosettes, the resulting computation of $r_{\mathrm{VA}}$ applied to SPEC data results in values that are 2-3 times those from using their general formula. Also, because the SPEC techniques used to compute both $V$ and $A_{\mathrm{SI}}$ are considerably different than $\mathrm{W} 03$, it leads one to question whether the good agreement between SPEC and W03 $r_{\mathrm{VA}}$ values is real or coincidental. Equivalent radius is most useful in radiative studies, and this question can likely only be answered by comparison with direct radiative measurements, such as volumetric multiwavelength scattering and absorption, which incorporate $r_{\mathrm{VA}}$ in a deterministic manner.

\section{d. Optical effects observed in 2002}

Visual observations from human observers, when available in 2001, suggested that $22^{\circ}$ and $46^{\circ}$ halos were only present when the CPI recorded relatively low concentrations of pristine columns and plates. Tape (1994) also observed that $22^{\circ}$ and $46^{\circ}$ halos, along with additional optical phenomena, were often observed in the presence of diamond dust. However, on occasion, he also reported a "mediocre" $22^{\circ}$ halo and a faint hint of a $46^{\circ}$ halo in the presence of precipitating bullet rosettes. Tape $(1994$, p. 49$)$ shows a photograph of a $22^{\circ}$ halo in the presence of precipitating rosettes; however, the sky conditions appear to be mostly blue sky with high, thin cirrus. Thus, the mediocre halo may be expected to be the result of pure bullet rosettes that formed at cold temperatures high in the atmosphere. No visual halos were observed in 2001 with overcast conditions when rosettes were precipitating. This is likely because the crystal types were not pure bullet rosettes, but instead rosette shapes, which include mixed habits that would not be expected to produce halos. Also, unlike the nearly clear blue sky seen in Tape's photograph with halos, the dark, overcast conditions observed during our deployment indicate thick clouds, which inhibit observations of halos because of multiple scattering.

As pointed out in the introduction to this paper, the light-scattering properties of ice crystals have a major impact on the earth's radiation budget. The logistical ease of operation at SPS (as compared with airborne measurements), the persistence of precipitating ice crystals, and the similarity in shape of SPS ice crystals to those found in cirrus (Lawson et al. 2006) are excellent reasons to make combined measurements of CPI images and scattering phase functions at SPS. During the 2002 field deployment one of the CPIs was connected in tandem with a polar nephelometer (Fig. 1), developed by the French Laboratoire de Meteorologie Physique (LaMP) (Gayet et al. 1997; Crépel et al. 1997). The LaMP PN has been used to measure scattering phase function at the surface and from an aircraft (Oshchepkov et al. 2000; Gayet et al. 1998).

The 2002 CPI dataset was examined to find time periods for which a particular crystal type dominated. Corresponding PN data were processed by LaMP personnel and provided to SPEC. One requirement of the time periods was that they persisted long enough that they could be subdivided into even shorter time periods that would be used to test the robustness of the phase function measurements. Another requirement was that extinction measurements collected individually by the $\mathrm{CPI}$ and PN were well correlated through the time periods, thereby giving confidence that each instrument was working well and sensing approximately the same volume of ice crystals. The phase functions were normalized because it is only the shape of the phase function that is of interest. A total of five time periods were found for which a particular crystal type dominated. Of these five, three time periods satisfied the test of good correlation between the CPI and PN extinction measurements.

Figure 12 shows a comparison of measurements from three time periods that met the requirements discussed above. Diamond dust (columns and plates) dominated for one of the time periods, for another plates alone dominated, and rosette shapes dominated the third time period. Time series, presented at the top of Fig. 12, for each major time period show the relative percentages of each crystal type, and also show the subperiods over which the phase functions were averaged. Each 

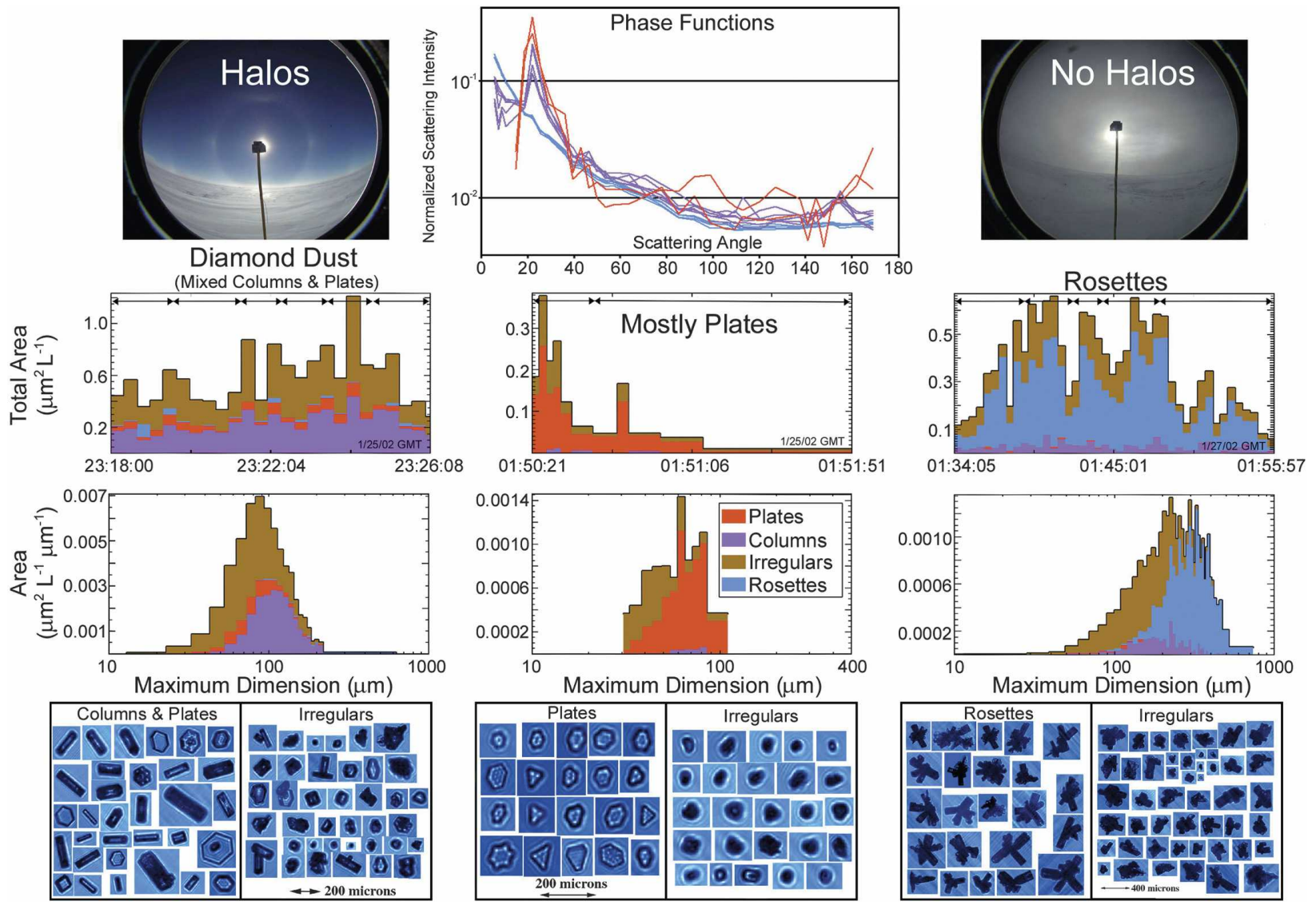

FIG. 12. CPI time series, PSDs, and sample images shown for three different crystal habit regimes at SPS: (left) mixed columns and plates, (middle) mostly plates, and (right) rosettes. Individual time periods for the PN measurements of phase functions are designated by arrows at the top of the time series. Sky photos shown for (top-left) mixed columns plates and (top-right) rosettes. Color key applies to all plots.

subperiod is indicated by the double-ended arrows at the top of time series in Fig. 12. Photos showing $22^{\circ}$ and $46^{\circ}$ halos during the diamond dust time period, and the absence of halos during the time period with rosette shapes are also shown at the top of the figure. The PSDs in the midregions of Fig. 12 give information on the size range of each crystal type, and typical CPI images for each major time period are shown at the bottom of the figure. Irregular crystal shapes are shown as well as the dominant crystal type to show how the irregular shapes in each region, to some extent, are similar to the dominant crystal type.

Of the three major time periods shown in Fig. 12, the rosettes and the mixed columns and plates time periods have sufficient duration and signal so that the phase function measurements, shown also at the top of Fig. 12 , appear robust, while the plates-only time section is much shorter, resulting in fewer and noisier measurements. The PN phase functions for each of the subperiods when rosette shapes dominated (shown in blue) are all very similar and nearly featureless. The phase functions for each of the columns and plates diamond dust subperiods (shown in violet) display strong $22^{\circ}$ halos and weak $46^{\circ}$ halos, and are also all reasonably similar. The corresponding sky photographs in Fig. 12 also show the absence of halos for the rosette shape occurrence and the presence of halos during a diamond dust event with mixed columns and plates. The phase functions for each of the plate-dominated subperiods (shown in red in Fig. 12) display a strong $22^{\circ}$ halo and a weak $46^{\circ}$ halo, but also have considerable noise resulting from the low signal. Average phase functions are shown in Fig. 13. The average of the (blue) rosetteshaped phase functions in Fig. 12 is black in Fig. 13, the average of the (violet) mixed columns and plates phase functions is dark gray in Fig. 13, and the average of the (red) mostly plates phase functions in Fig. 12 is light gray in Fig. 13. The average phase functions show the same predominant features as the individual phase functions, that is, a strong $22^{\circ}$ halo in mixed columns 


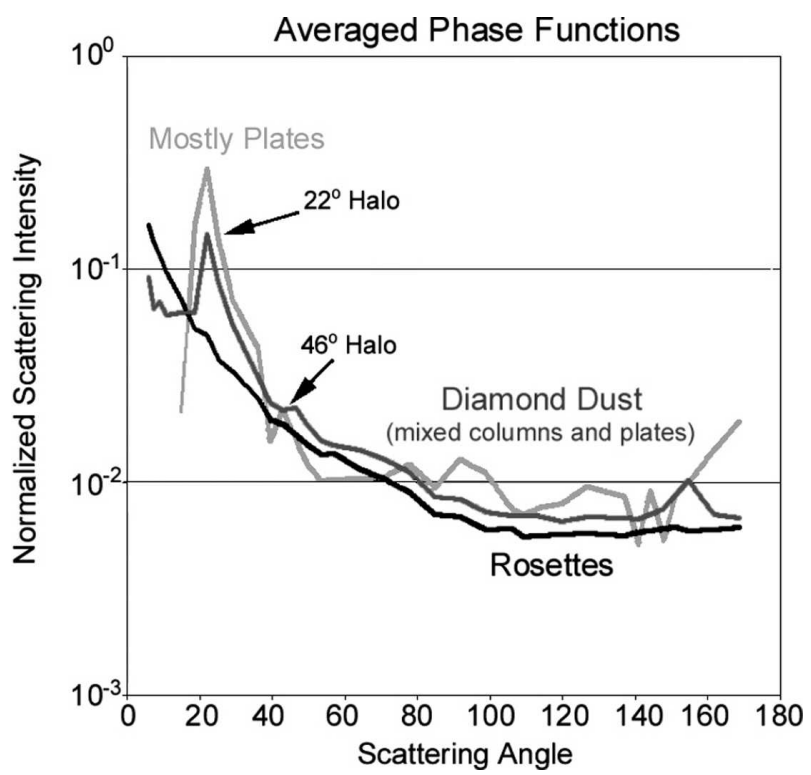

FIG. 13. Average of phase functions shown in Fig. 12 for rosettes (black line), mixed columns and plates (dark gray), and plates (light gray line).

and plates and mostly plates, an indication of a $46^{\circ}$ halo in the mixed columns and plates and mostly plates, and a featureless phase function for rosette shapes. There is also indication of an "ice bow" in the mixed columns and plates phase function near $155^{\circ}$. Shcherbakov et al. (2006) also observed an ice bow, and $22^{\circ}$ and $46^{\circ}$ halos in PN data collected in diamond dust at SPS.

CPI measurements in cirrus clouds show that the major identifiable crystal type is the rosette shape, while pristine columns and plates are generally rare (Lawson et al. 2006). This may explain the relative scarcity of atmospheric halos observed in the presence of cirrus clouds (Mishchenko et al. 1996). Ray tracing (e.g., Takano and Liou 1995) shows that pure bullet rosettes should produce $22^{\circ}$ and $46^{\circ}$ halos, so there may be other explanations as well. For example, Baran et al. (2005) found that the PN-measured phase function (for the same time period with rosette shapes examined here) agreed best with a model that predicted scattering from an ensemble of ice crystals. The measurements in Figs. 12 and 13 have implications for the light-scattering properties of cirrus clouds, which play a significant role in the earth energy balance (Liou 1986), cloud feedback on climate (Stephens et al. 1990) and global climate models (Kristjánsson et al. 2000), and obtaining reliable inversion products from remote observations (Labonnote et al. 2000). The CPI and PN measurements at SPS are also valuable to compare with theoretical models that predict light scattering from a single ice crystal (e.g., Shcherbakov et al. (2006) and an ensemble of ice crystals (e.g., Baran et al. 2005).

\section{Summary}

Over 900000 ice crystals were imaged by CPIs during the period of 1-8 February 2001 when the surface temperature ranged from $-30^{\circ}$ to $-39^{\circ} \mathrm{C}$. Of these, 721572 CPI images were $>50 \mu \mathrm{m}$ and sorted into habit categories. Pristine "diamond dust" ice crystals were usually observed with sizes $<\approx 150 \mu \mathrm{m}$ and consisted of thick plates/short columns, columns, and plates. Diamond dust was typically associated with thin, relatively high (1-2 km) clouds. The sun was usually visible through these clouds and optical effects were often observed. Budding rosettes, mixed-habit rosettes, and platelike polycrystals, often observed with side planes, were lumped into a category called "rosette shapes," which were typically less than $\approx 250 \mu \mathrm{m}$ in size and were observed under low $(<1 \mathrm{~km})$, overcast clouds. Pure bullet rosettes were rarely observed, presumably because the atmosphere below $500 \mathrm{hPa}$, where clouds were most often observed, was rarely colder than $-40^{\circ} \mathrm{C}$, the maximum threshold temperature at which Bailey and Hallett (2004) observed growth of pure bullet rosettes in the laboratory. Limited balloon observations (Mahesh et al. 2001) showed that the low, overcast clouds often contained supercooled liquid water at temperatures between $-25^{\circ}$ and $-35^{\circ} \mathrm{C}$.

When sorted by number, rosette shapes constitute $30 \%$ of the crystals, diamond dust (columns, thick plates, and plates) $45 \%$, and irregular shapes $25 \%$. When sorted by area, rosette shapes comprise $50 \%$, diamond dust $30 \%$, and irregular shapes $20 \%$. By mass, the percentages are $57 \%$ rosette shapes, $23 \%$ diamond dust, and $20 \%$ irregular shapes. Thus, the rosette shapes, while less frequent in occurrence, accounted for the majority of the area and mass of ice crystals observed at SPS during 1 through 8 February. Irregularly shaped ice crystals were observed at SPS in all types of falling ice crystal precipitation and in blowing snow, which was prevalent when the wind speed was $>\approx 4 \mathrm{~m} \mathrm{~s}^{-1}$. Irregular ice crystals in blowing snow were observed to generally have more rounded edges than irregular shapes in precipitation.

Our studies support previous findings (e.g., Ohtake and Yogi 1979; W03) that rosette shapes account for the majority of the precipitating ice crystal mass in both summer and winter. Depending on particle habit, SPEC mean values of equivalent particle radius in summer are close in value or slightly larger than W03 mean values in winter. W03 also computed mean equivalent radius values for diamond dust from limited summertime measurements, and from previous measurements by Kikuchi and Hogan (1979). In both cases, the mean equivalent radius of summertime diamond dust was larger 
than in winter, and also agreed well with our summertime mean value. The largest difference in mean equivalent radius measurements was for blowing snow; the mean wintertime value is $11 \mu \mathrm{m}$, based on W03 measurements, and the mean summertime value is 17 $\mu \mathrm{m}$, based on our findings.

In February 2002, SPEC added a LaMP polar nephelometer in tandem with one of the CPIs, in order to make measurements of scattering phase function. Phase functions for diamond dust and for rosetteshaped crystals are presented. Diamond dust phase functions have robust $22^{\circ}$ and $46^{\circ}$ peaks that were correlated with visual observations of halos when the sun was shinning through thin, high scattered clouds. Atmospheric halos were not seen when CPI measurements showed that rosette-shaped ice particles were falling from a low, thick overcast cloud, and the phase function measurements were robust and featureless.

Acknowledgments. This research was sponsored by the National Science Foundation under Grant OPP9909593. We are grateful to Steve Warren, Von Walden, Richard Brandt, and Michael Town for their guidance and assistance at SPS, and to Steve Warren and Matthew Bailey for their insightful reviews of the manuscript. We also thank Raytheon Polar Services Corporation for the excellent logistics and field support provided to SPEC personnel during the course of this research.

\section{APPENDIX}

\section{Acceptance Criteria Used to Classify Ice Particle Images by Habit}

This appendix presents the acceptance criteria that were used in this paper to automatically classify particle shapes into nine categories, listed as 1 through 9 below. Each particle image is subjected to each criterion. If a particle image satisfies any of the first eight (mutually exclusive) criteria, it is accepted within that criterion and classified accordingly. If the particle does not meet any of the first eight criteria, it is classified in the ninth category, that is, "irregular."

Definitions of the parameters used in the nine image classification criteria are listed below. The following variables are used in these criteria. "Focus" is a value that quantifies sharpness of the particle outline on a scale between 0 and 100. Focus of less than 20 is considered to be too blurry to analyze. "Cutoff" is the probable percentage of the total image area that lies outside of the image and has values between 0 (all in) and 99 (almost all out). "Crystal" has two default val- ues, 15 as ice or 1 as water, based on its overall roundness. "Length" is the length of the particle along the major axis $(\mu \mathrm{m})$. "Width" is the width of the particle perpendicular to the major axis $(\mu \mathrm{m})$. "Perimeter" is the perimeter of the particle $(\mu \mathrm{m})$. Coefficients "h1h6" are determined from "radial harmonics," which are determined by drawing a radius from the image centroid to each pixel on the perimeter, making a series from these radii, and performing a fast Fourier transform on the resulting series; h1-h6 are the first six harmonic frequencies. "Hole area" is the fraction of image area above the $(50 \%)$ shadow depth threshold.

\section{a. Spheroids and small plates}

Spheroids and small plates (category 1) have focus greater than 20 and cutoff equal to 0 and crystal equal to 1 or length less than or equal to 30 .

\section{b. Long columns}

Long columns (category 2) have focus greater than 20 and cutoff equal to 0 and length greater than 30 and width less than 200 and [length greater than 2.0 times the width and absolute value of (perimeter $\times$ perimeter $-4.0 \times$ length $\times$ length $-8.0 \times$ area) less than $0.500 \times$ perimeter $\times$ perimeter $+0.9 \times$ area $+0.9 \times$ length $\times$ length and $\mathrm{h} 2$ greater than 0.13 and h1 less than 0.1 and $h 3$ less than 0.1].

\section{c. Thick plates/short columns}

Thick plates/short columns (category 3 ) have focus greater than 20 and cutoff equal to 0 and length greater than 30 and width less than 200 and [length less than or equal to $2.0 \times$ width and perimeter $\times$ width/area greater than $2.02 \times$ the square root of $(1+$ width $\times$ width/length/length $) \times(1+$ width/length $)$ and perimeter $\times$ width/area less than $2.2 \times$ the square root of $(1+$ width $\times$ width/length/length $) \times(1+$ width/length $)$ and the absolute value of (perimeter $\times$ perimeter $4.0 \times$ length $\times$ length $-8.0 \times$ area $)$ less than $0.5 \times$ perimeter $\times$ perimeter $+0.9 \times$ area $+0.9 \times$ length $\times$ length and $\mathrm{h} 2$ greater than 0.13 and $\mathrm{h} 1$ less than 0.1 and h3 less than 1.539].

\section{d. Plates}

Plates (category 4) have focus greater than 20 and equal to 0 and length greater than 30 and length less than 500 and $(\langle(\mathrm{h} 2$ greater than 0.01 and $\mathrm{h} 3$ less than 0.02 and $\mathrm{h} 4$ greater than 0.01 and $\mathrm{h} 5$ less than 0.02 and h6 greater than 0.01 and hole area greater than 20) or (h2 greater than 0.01 and h3 less than 0.02 and h5 less than 0.02 and h6 greater than 0.01 and length less than 
$1.6 \times$ width and length greater than 50 and h4 less than 0.02 ) or \{length greater than 75 and $h 2$ greater than 0.01 and length less than $1.6 \times$ width and [ $(\mathrm{h} 4$ greater than 0.01 ) or (h6 greater than 0.01)] and h3 less than 0.02 and hole area greater than 10$\}\rangle)$.

\section{e. Bullet rosettes}

Bullet rosettes (category 5) have focus greater than 20 and cutoff equal to 0 and length greater than 200 and width greater than or equal to 100 and area/(length $\times$ width) greater than 0.7 and area/(length $\times$ width) less than 0.9 and [length greater than $2.0 \times$ width and the absolute value of (perimeter $\times$ perimeter $-4.0 \times$ length $\times$ length $-8.0 \times$ area) less than $0.500 \times$ perimeter $\times$ perimeter $+0.9 \times$ area $+0.9 \times$ length $\times$ length and $\mathrm{h} 2$ greater than 0.13 and $\mathrm{h} 1$ less than 0.1 and $\mathrm{h} 3$ less than 0.1].

\section{f. Budding rosettes}

Budding rosettes (category 6) have [focus greater than 20 and cutoff equal to 0 and the square root of (area)/perimeter less than 0.20 and length greater than 40 and length less than 150] and not [the square root of (area)/perimeter less than 0.17 and length greater than 80].

\section{g. Rosettes}

Rosettes (category 7) have [focus greater than 20 and cutoff equal to 0 and the square root of (area)/ perimeter less than 0.17 and length greater than 80 ] or [the square root of (area)/perimeter less than 0.20 and length greater than 150].

\section{h. Complex crystals}

Complex crystals (category 8) have (focus greater than 20 and cutoff equal to 0 and width greater than 100 ) and not \{length less than 200 and [the square root of (area)/perimeter less than 0.22 and length greater than 40$]\}$.

\section{i. Irregulars}

Irregulars (category 9) have focus greater than 20 and cutoff equal to 0 and length greater than 30 .

\section{REFERENCES}

Auriol, F., J.-F. Gayet, G. Febvre, O. Jourdan, L. Labonnote, and G. Brogniez, 2001: In situ observation of cirrus scattering phase functions with $22^{\circ}$ and $46^{\circ}$ halos: Cloud field study on 19 February 1998. J. Atmos. Sci., 58, 3376-3390.

Bacon, N. J., M. B. Baker, and B. D. Swanson, 2003: Initial stages in the morphological evolution of vapour-grown ice crystals: A laboratory investigation. Quart. J. Roy. Meteor. Soc., 129, 1903-1927.
Bailey, M., and J. Hallett, 2004: Growth rates and habits of ice crystals between $-20^{\circ}$ and $-70^{\circ}$ C. J. Atmos. Sci., 61, 514-544.

Baker, B. A., and R. P. Lawson, 2006a: In situ observations of the microphysical properties of wave, cirrus, and anvil clouds. Part I: Wave clouds. J. Atmos. Sci., in press.

$\longrightarrow$, and 2006b: Improvement in determination of ice water content from two-dimensional particle imagery. Part I: Image-to-mass relationships. J. Appl. Meteor. Climatol., 45, $1282-1290$

Baran, A. J., V. N. Shcherbakov, B. A. Baker, J. F. Gayet, and R. P. Lawson, 2005: On the scattering phase-function of nonsymmetric ice-crystals. Quart. J. Roy. Meteor. Soc., 131, 1-8.

Bromwich, D. H., 1988: Snowfall in high southern latitudes. Rev. Geophys., 26, 146-168.

Campbell, J. R., D. L. Hlavka, E. J. Welton, C. J. Flynn, D. D. Turner, J. D. Spinhirne, V. S. Scott, and I. H. Hwang, 2002: Full-time, eye-safe cloud and aerosol lidar observation at atmospheric radiation measurement program sites: Instrument and data processing. J. Atmos. Oceanic Technol., 19, 431-442.

Crépel, O., J.-F. Gayet, J.-F. Fournol, and S. Oshchepkov, 1997: A new airborne polar nephelometer for the measurements of optical and microphysical cloud properties. Part II: Preliminary tests. Ann. Geophys., 15, 460-470.

Gayet, J.-F., O. Crépel, J.-F. Fournol, and S. Oshchepkov, 1997: A new airborne polar nephelometer for the measurements of optical and microphysical cloud properties. Part I: Theoretical design. Ann. Geophys., 15, 451-459.

_ and Coauthors, 1998: In situ measurements of the scattering phase function of stratocumulus, contrails, and cirrus. Geophys. Res. Lett., 25, 971-974.

Grenfell, T. C., and S. G. Warren, 1999: Representation of a nonspherical ice particle by a collection of independent spheres for scattering and absorption of radiation. J. Geophys. Res., 104, 31 697-31 709.

Hogan, W. H., 1975: Summer ice crystal precipitation at the South Pole. J. Appl. Meteor., 14, 246-249.

Inoue, M., T. Ohtake, and G. Wakahama, 1984: Summer precipitation onto the south polar plateau. Mem. Natl. Inst. Polar Res. Spec. Issue Japan, 34, 70-86.

Kikuchi, K., 1970: Peculiar shapes of solid precipitation observed at Syowa Station, Antarctica. J. Meteor. Soc. Japan, 48, 243249.

- and A. W. Hogan, 1979: Properties of diamond dust type ice crystals observed in summer season at Amundsen-Scott South Pole Station, Antarctica. J. Meteor. Soc. Japan, 57, 180-190.

Korolev, A. V., G. A. Isaac, and J. Hallett, 1999: Ice particle habits in Arctic clouds. Geophys. Res. Lett., 26, 1299-1302.

Kristjánsson, J. E., J. M. Edwards, and D. L. Mitchell, 2000: Impact of a new scheme for optical properties of ice crystals on climates of two GCM's. J. Geophys. Res., 105, $10063-10079$.

Labonnote, L., G. Brogniez, M. Doutriaux-Boucher, J.-C. Buriez, J.-F. Gayet, and H. Chepfer, 2000: Modeling of light scattering in cirrus clouds with inhomogeneous hexagonal monocrystals. Comparison with in-situ and ADEOS-POLDER measurements. Geophys. Res. Lett., 27, 113-116.

Lawson, R. P., B. A. Baker, C. G. Schmitt, and T. L. Jensen, 2001: An overview of microphysical properties of Arctic clouds observed in May and July during FIRE.ACE. J. Geophys. Res., 106, 14 989-15 014.

, Q. Mo, and B. Pilson, 2006: In situ observations of the microphysical properties of wave, cirrus, and anvil clouds. Part II: Cirrus clouds. J. Atmos. Sci., in press. 
Liou, K. N., 1986: Influence of cirrus clouds on weather and climate processes: A global perspective. Mon. Wea. Rev., 114, 1167-1199.

Magono, C., and C. W. Lee, 1966: Meteorological classification of natural snow crystals. J. Fac. Sci. Hokkaido Univ. Ser. 7, 2 (4), 320-335.

Mahesh, A., V. P. Walden, and S. G. Warren, 2001: Ground-based infrared remote sensing of cloud properties over the Antarctic Plateau. J. Appl. Meteor., 40, 1279-1294.

Mishchenko, M. I., W. B. Rossow, A. Macke, and A. A. Lacis, 1996: Sensitivity of cirrus cloud albedo, bidirectional reflectance, and optical thickness retrieval accuracy to ice-particle shape. J. Geophys. Res., 101, 16 973-16 985.

Mitchell, D. L., R. Zhang, and R. L. Pitter, 1990: Massdimensional relationships for ice particles and the influence of riming on snowfall rates. J. Appl. Meteor., 29, 153-163.

Ohtake, T., 1978: Atmospheric ice crystals at the South Pole in summer. Antarct. J. U.S., 13, 174-175.

- , and T. Yogi, 1979: Winter ice crystals at South Pole. Antarct. J. U.S., 14, 201-203.

Orikasa, N., and M. Murakami, 1997: A new version of hydrometeor videosonde for cirrus cloud observations. J. Meteor. Soc. Japan, 75, 1033-1039.

Oshchepkov, S., H. Isaka, J.-F. Gayet, A. Sinyuk, F. Auriol, and S. Havemann, 2000: Microphysical properties of mixed-phase and ice clouds retrieved from in situ airborne polar nephelometer measurements. Geophys. Res. Lett., 27, 209212.

Pruppacher, H. R., and J. D. Klett, 1997: Microphysics of Clouds and Precipitation. $2 \mathrm{~d}$ ed. D. Reidel, 954 pp.

Rao, R. M., and A. S. Bopardikar, 1998: Wavelet Transforms: Introduction to Theory \& Applications. Prentice Hall, 336 pp.
Schmitt, C. G., and A. J. Heymsfield, 2005: Total surface area estimates for individual ice particles and particle populations. J. Appl. Meteor., 44, 467-474.

Shcherbakov, V., J.-F. Gayet, B. A. Baker, and R. P. Lawson, 2006: Light scattering by single natural ice crystals. J. Atmos. Sci., 63, 1513-1525.

Shimizu, H., 1963: 'Long prism' crystals observed in precipitation in Antarctica. J. Meteor. Soc. Japan, 41, 305-307.

Smiley, V. N., B. M. Whitcomb, B. M. Morley, and J. A. Wharburton, 1980: Lidar determinations of atmospheric ice crystal layers at South Pole during clear-sky precipitation. J. Appl. Meteor., 19, 1074-1090.

Stephens, G. L., S.-C. Tsay, P. W. Stackhouse, and P. J. Flatau, 1990: The relevance of the microphysical and radiative properties of cirrus clouds to climate and climatic feedback. $J$. Atmos. Sci., 47, 1742-1753.

Takano, Y., and K. N. Liou, 1995: Radiative transfer in cirrus clouds. Part III: Light scattering by irregular ice crystals. $J$. Atmos. Sci., 52, 818-837.

Tape, W., 1994: Atmospheric Halos. Antarctic Research Series, Vol. 64, Amer. Geophys. Union, 143 pp.

Walden, V. P., S. G. Warren, and E. Tuttle, 2003: Atmospheric ice crystals over the Antarctic Plateau in winter. J. Appl. Meteor., 42, 1391-1405.

, M. E. Ellison, R. E. Brandt, M. S. Town, S. R. Hudson, and R. M. Jones, 2005: Properties of super-cooled water clouds over South Pole. Preprints, Eighth Conf. on Polar Meteorology and Oceanography, San Diego, CA, Amer. Meteor. Soc., CD-ROM, 6.1.

Warren, S. G., 1996: Antarctica. Encyclopedia of Climate and Weather, Vol. 1. S. H. Schneider, Ed., Oxford University Press, 32-39. 